\title{
Integrated Fault Evaluation Through Fusion Algorithm Supported by Kalman Filter
}

\author{
Sadra Mousavi*, Duygu Bayram Kara, Sahin Serhat Seker \\ Electrical Engineering Department, Istanbul Technical University, Istanbul 34469, Turkey
}

Corresponding Author Email: sadramousavi@itu.edu.tr

https://doi.org/10.18280/ts.370610

Received: 9 August 2020

Accepted: 20 November 2020

\section{Keywords:}

Kalman filter, vibration signal, aging process, sensor validation, data fusion, fault detection, health information

\begin{abstract}
An Integrated Fault Evaluation (IFE) process is proposed in this study. It includes Sensor Validation (SV), Fault Detection (FD) and Fault Source Identification (FSI). The proposed algorithm employs data fusion algorithm enhanced by Kalman filter (KF). As the case study, vibration signals representing different aging states of an induction motor are used. The vibration data collected from two identical sensors with different measurement and process noises are achieved. Through the statistical and frequency domain characteristics, IFE is realized. The most prominent contribution of the study is the capability of distinction between the aging of the system and the process problems. For this aim, a rate representing the healthiness, which can discern the impact of the process noise and system aging, is calculated.
\end{abstract}

\section{INTRODUCTION}

Kalman filter (KF) which is initially proposed in 60's, first employed as state estimator thanks to its iterative nature $[1,2]$. Then the algorithm is adapted to different applications such as target motion analysis [3], real-time thermal monitoring of an induction machine [4], etc.

In the recent years KF raises its popularity as a fusion algorithm in many practical applications such as, remote sensing, object tracing, battle-field surveillance [5], etc. The major advantage of KF is the outstanding operation capability in real time applications through its robustness to high signal to noise ratios (SNR). Hence, this method is preferred widely as a fusion algorithm to be employed by multiple sensor information [6].

Moreover, as a result of filtering property of $\mathrm{KF}$, fusion algorithms become very powerful for fault detection (FD) applications [7-9]. For example, in the reference [8], a KFbased FD technique is proposed for DC motors using residuals. In this paper, current and speed signals are assumed as state vectors. Variation between the real and the estimated states is indicated as residuals. The study also detects overload fault in presence of several uncertainties which are isolated successfully using KF. However, in reference [10], FD is achieved through residuals in linear dual motor system, despite the existence of noise. The residual signal is generated based on KF, then a threshold is determined to detect the sensor fault and actuator fault. Kalman filter is widely used in controller applications for electric machinery. It is usually employed as the observer algorithm. For example, in literature [11] a predictive direct torque controller is enhanced by KF which is used to estimate flux. KF is used as an estimator for secondary current and induced flux linkages of a linear IM [12]. By the estimation of KF a total least square EXIN neuron is trained as the observer. $\mathrm{KF}$ is also used for sensorless vector control for IMs. According to Boukhnifer et al. [13], a KF based fault tolerant control algorithm is proposed for an IM to eliminate the speed sensor failure.
It is well-known that FD techniques can be applied using various types of signals for electric machinery. For example, in papers [14-17], phase current [18], angular velocity or temperature [19]. Vibration signal is widely used for FD applications in electrical machinery. Because of its stochastic nature, it is very favorable for both the statistical and spectral investigations [20-23]. Various types of failures such as bearing fault, rotor related faults and winding faults are mentioned in surveys to be detected through vibration signal [24]. Bearing faults is the most common fault in EMs, which can be detected easily either by the electrical or vibration signals [25-27]. Further, vibration signals carry lots of information on the bearing health of the EM that is why it is preferred for such mechanical faults [28]. Bearing FD using vibration signal is studied in the literature widely through various methods and algorithms [29-32]. For instance, Reference [33] uses vibration signals to diagnose bearing fault through an intelligent filter (adaptive linear neuron) by extracting features and running classification algorithms. Since the bearing fault arises between $2-4 \mathrm{kHz}$, in Reference [34], it is detected through a neural network which is trained by the coherence of vibration and stator current signals.

On the other hand, FD through KF using vibration signal is very limited in the literature. For example, in Reference [35], first, the model of flux switching permanent magnet motor using electrical and mechanical equations is presented and then an observer system empowered by KF is designed to generate the residual function from predicted and measured vibration for FD and localization purposes.

In spite of that much knowledge and application of FD and $\mathrm{KF}$, data fusion through KF using vibration signals has not met by the authors in the literature.

In this study, an application employing data fusion algorithm empowered by KF is proposed. Vibration signals acquired for different aging states on an induction motor (seven cases from healthy to aged) are employed as the case study. An Integrated Fault Evaluation (IFE) application is realized including Sensor Validation (SV), Fault Detection 
(FD) and Fault Source Identification (FSI). FSI determines whether the fault is originated by the system, process, or sensors.

The proposed method has two major parts; the first part observes the effect of measurement noise. Measurement data is duplicated with different noises representing sensor information acquired from different sensors. As a result, IFE and sensor validation (SV) applications are proposed by observing the statistical and frequency domain characteristics aiming a contribution on impact of measurement noise. Then, in the second part, process noise is investigated deeply which is totally new for the literature. In order to distinguish the process noise and the aging of the system, a health rate is proposed through vibration signals.

The study provides a brief mathematical background of KF in Section II. Section III, accounts for the experiment with its outputs and data acquisition system. Section IV, presents a FD application utilizing data fusion through KF under different measurement noises. In section $\mathrm{V}$, a health rate is proposed to distinguish between the process noise and the aging in the system. Finally, the paper concludes at section VI with original contributions.

\section{MATHEMATICAL BACKGROUND}

In this section a brief mathematical background for $\mathrm{KF}$ and data fusion through KF algorithm is presented [36-38].

\subsection{Kalman filter equations}

In the KF model, the pervious state of a system is used to calculate the next state by Eq. (1):

$$
\boldsymbol{x}_{k}=\boldsymbol{F} \boldsymbol{x}_{k-1}+\boldsymbol{G} \boldsymbol{u}_{k-1}+\boldsymbol{w}_{k-1}
$$

where, $\boldsymbol{x}$ is the state vector, $\boldsymbol{F}$ is the state matrix, $\boldsymbol{G}$ is the input matrix, $\boldsymbol{u}$ is input vector and $\boldsymbol{w}$ is the process noise vector. The output vector also, can be obtained by the measurement and it can be expressed as a function of the state vector $\boldsymbol{x}$ as seen in Eq. (2):

$$
\boldsymbol{y}_{k}=\boldsymbol{H} \boldsymbol{x}_{k}+\boldsymbol{v}_{k}
$$

where, $y$ is the output vector, $v$ is the observation matrix and $v$ is the measurement noise vector.

Note that, $\boldsymbol{w}$ and $\boldsymbol{v}$ are normal distributed Gaussian noises with covariance matrix $\boldsymbol{Q}$ and $\boldsymbol{R}$, respectively [38].

The KF algorithm contains the prediction stage and the measurement updates. The equations of these stages are presented as below [36-38].

Prediction stage:

$$
\begin{gathered}
\widehat{\boldsymbol{x}}_{k \mid k-1}=\boldsymbol{F} \widehat{\boldsymbol{x}}_{k-1}+\boldsymbol{G} \boldsymbol{u}_{k-1} \\
\boldsymbol{P}_{k \mid k-1}=\boldsymbol{F} \boldsymbol{P}_{k-1} \boldsymbol{F}^{T}+\boldsymbol{Q}_{t}
\end{gathered}
$$

Measurement update:

$$
\begin{gathered}
\boldsymbol{K}_{k}=\boldsymbol{P}_{k \mid k-1} \boldsymbol{H}^{T}\left(\boldsymbol{H} \boldsymbol{P}_{k \mid k-1} \boldsymbol{H}^{T}+\boldsymbol{R}_{k}\right)^{-1} \\
\widehat{\boldsymbol{x}}_{k}=\widehat{\boldsymbol{x}}_{k \mid k-1}+\boldsymbol{K}_{k}\left(\widehat{\boldsymbol{y}}_{k}-\boldsymbol{H} \widehat{\boldsymbol{x}}_{k \mid k-1}\right)
\end{gathered}
$$

$$
\boldsymbol{P}_{k}=\left(\boldsymbol{I}-\boldsymbol{K}_{k} \boldsymbol{H}\right) \boldsymbol{P}_{k \mid k-1}
$$

where, $\widehat{\boldsymbol{x}}_{\boldsymbol{k}}$ is predicted state vector, $\boldsymbol{P}_{\boldsymbol{k}}$ is state error covariance matrix, $\boldsymbol{K}_{k}$ is Kalman gain matrix, $\widehat{\boldsymbol{y}}_{k}$ is measurement output and $\boldsymbol{I}$ is identity matrix. $\widehat{\boldsymbol{x}}_{0}$ and $\boldsymbol{P}_{0}$ which are the initial state estimation matrix and the initial state error covariance matrix, respectively.

First, the state vector $\widehat{\boldsymbol{x}}_{k}$ and the state error covariance matrix $\boldsymbol{P}_{k}$ are estimated in the prediction stage. Thereafter, the values of the Kalman Gain matrix $\boldsymbol{K}$, predicted state vector and the state error covariance matrix are updated in measurement update stage.

\subsection{Data fusion through Kalman filter}

In fusion algorithm, the assignment of the observation matrix is crucial. To map the state vector into the output vector, observation matrix $\boldsymbol{H}$ is used. Hence, $\boldsymbol{H}$ matrix ensures a linear transformation in linear KF algorithm. $\boldsymbol{H}$ matrix indicates which state variables are included and which are not. Moreover, it represents dependence of the output vector to the state vector. Furthermore, $\boldsymbol{H}$ matrix can be used for state combination which serves as a fusion tool. For example, in a system which the measured output depends on two states, the observation matrix is assigned as seen in Eq. (8), providing the linear combination of input states [37]:

$$
\begin{gathered}
\boldsymbol{H}=\left[\begin{array}{ll}
1 & 1
\end{array}\right] \\
\boldsymbol{y}_{k}=\boldsymbol{H} \boldsymbol{x}_{k} \Rightarrow \boldsymbol{y}_{k}=\left[\begin{array}{ll}
1 & 1
\end{array}\right]\left[\begin{array}{l}
\boldsymbol{x}_{1} \\
\boldsymbol{x}_{2}
\end{array}\right]=\boldsymbol{x}_{1}+\boldsymbol{x}_{2}
\end{gathered}
$$

Kalman algorithm satisfies small sample theory [39] but Kalman filter fusion algorithm may not work properly in small samples. Consequently, the fusion algorithm is run with different sized data. It is noticed that the algorithm does not succeed in small sized data. The outputs for a small sample (29 data points) and larger data are given in the Figure 1.

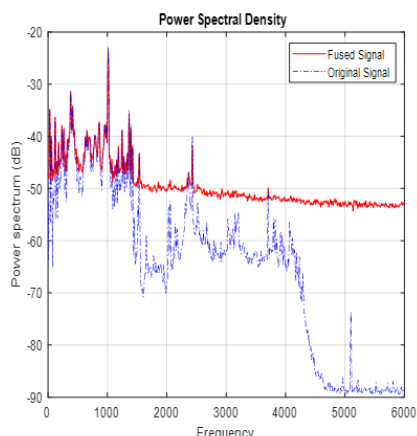

(a)

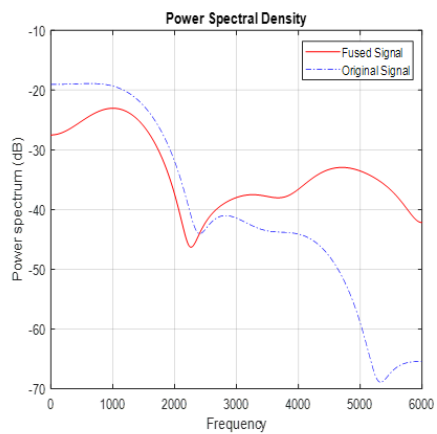

(b)
Figure 1. (a) Kalman algorithm with large data (b) Kalman algorithm with small data points

\section{EXPERIMENTAL SETUP AND DATA ACQUISITION SYSTEM}

The vibration data, is collected from an accelerated aging experiment having 7 cycles. At the end of the seventh cycle, the motor is completely defective. In this process, two methods are applied to achieve aging on the system. These are thermalchemical aging (chemical) and electrical discharge machine 
(mechanical). In the chemical method the induction motor (IM) is exposed to severe thermal conditions. In the mechanical method, $30 \mathrm{~V}$ is applied to the shaft of the motor, to create a bearing fault. The experiment is verified on three identical 5 HP squirrel cage induction motors to validate the process. The test motors are loaded by a $3 \mathrm{~kW}, 1,800 \mathrm{rpm}$ dynamometer, excited by $0-2 \mathrm{~A}, 0-200 \mathrm{~V}$ dc and loaded with $21.63 \Omega$ resistance. The technical information about the test motors is mentioned in Table A.1 which exists in Appendix [24].

The vibration data are acquired through NISCXI signal conditioning interface. They are also, sampled with $12 \mathrm{kHz}$ sampling rate. The antialiasing filter which is utilized in the DAQ system is NISCXI-1142 eight-order elliptic low pass filter with $4 \mathrm{kHz}$ cutoff frequency, $-80 \mathrm{~dB}$ stop band and 135 $\mathrm{dB} /$ octave roll-off $[24,40]$.

Table 1. Basic statistical properties of aging cycles

\begin{tabular}{cccc}
\hline Aging cycles & I. Means & II. Std Dev & Variances \\
\hline Initial & 0.0016 & 0.1135 & 0.0129 \\
Cycle 1 & 0.0014 & 0.1553 & 0.0241 \\
Cycle 2 & 0.0012 & 0.2082 & 0.0433 \\
Cycle 3 & 0.0013 & 0.2894 & 0.0837 \\
Cycle 4 & 0.0009 & 0.3275 & 0.1073 \\
Cycle 5 & 0.0010 & 0.3548 & 0.1259 \\
Cycle 6 & 0.0005 & 0.4147 & 0.1720 \\
Cycle 7 & 0.0030 & 0.6040 & 0.3648 \\
\hline
\end{tabular}

Statistical properties for each aging cycle are presented in Table 1. Moreover, time domain and spectral representations of the all signals are demonstrated in Figure 2. During the aging process, mean values do not vary, however, enormous changes are observed in standard deviations (Std Dev) and variances (Table 1). Consequently, the amplitude of the vibration signals in time domain increases in each cycle. Furthermore, the amplitudes of the frequency components between $2-4 \mathrm{~Hz}$ increase which indicates the bearing fault (Figure 2).
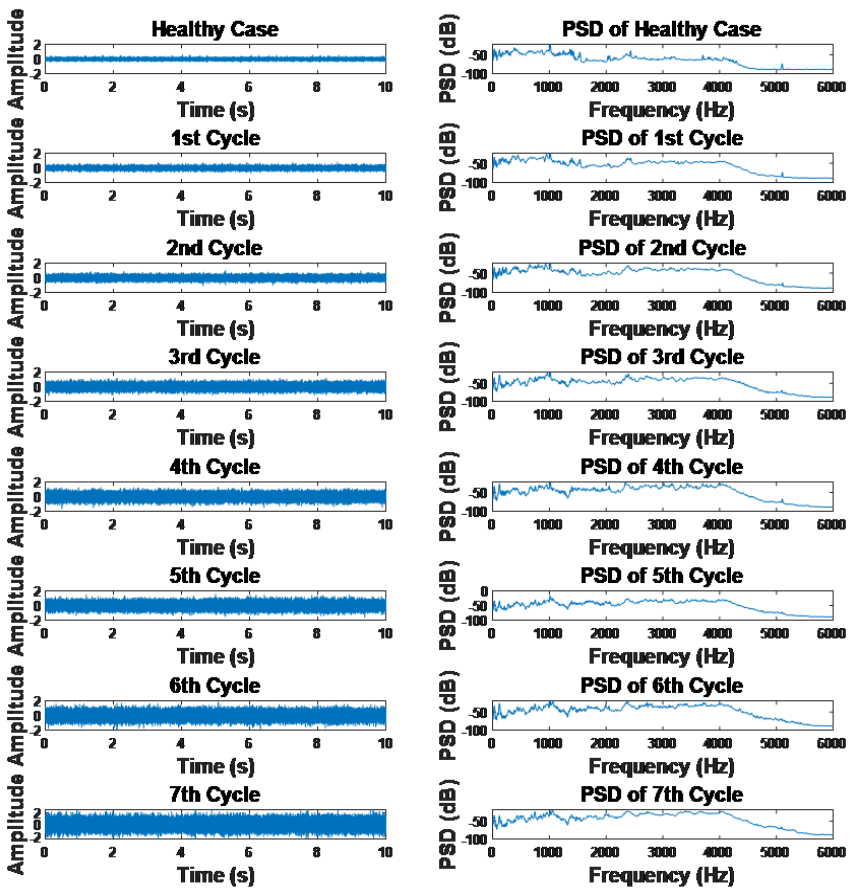

Figure 2. Time and frequency domain representations of the vibration signals

\section{INTEGRATED FAULT EVALUATION}

Integrated Fault Evaluation (IFE) process can be presented in two section. The first one is SV and FD.

Distinguishing the fault which is originated whether from the sensors or the system is an original contribution. It requires to observe both statistical - spectral properties of the sensor outputs. For this reason, the proposed algorithm cannot be mention as a simple FD operation which relies on a signal only. For a system with two different sensor information, fusion algorithm supported by KF is used to eliminate the faulty sensor. By this way, the possibility of fault for the sensors is deducted.

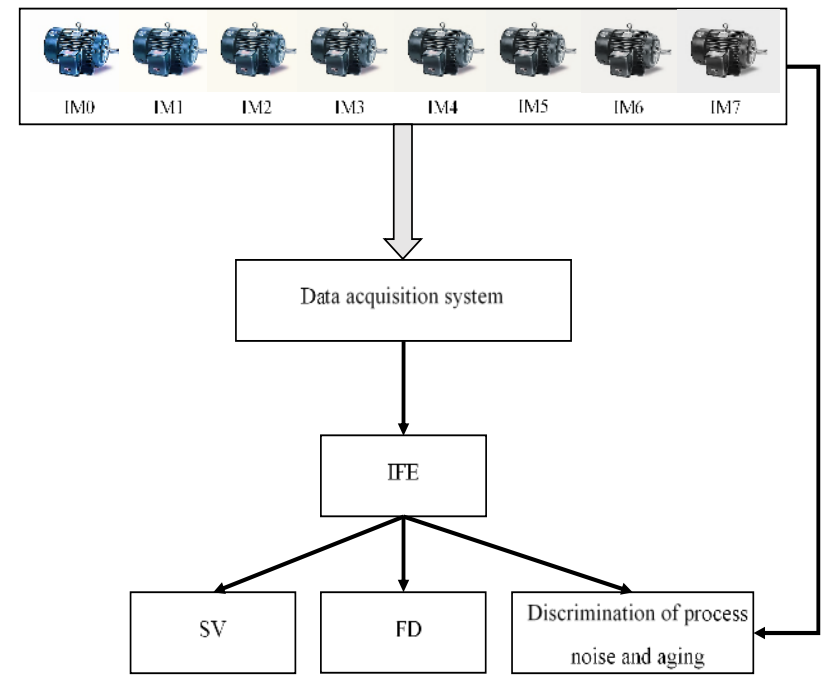

Figure 3. The flowchart of the study

\begin{tabular}{|ll|}
\hline 1. & Begin \\
\hline 2. & Get the vibration signal \\
\hline 3. & Making the process noise vector \\
\hline 4. & Making the measurement vectors \\
\hline 5. & $\begin{array}{l}\text { Obtain the output of the sensor } 1 \text { including the } \\
\text { measurement noise and bias }\end{array}$ \\
\hline 6. & Obtain the output of the sensor 2 including the \\
& measurement noise and bias
\end{tabular}

Figure 4. The pseudo code for the algorithm 
The second part is focused on the distinction of process fault and system fault. Since the process fault also increases the variance and standard deviation, so it can easily be confused with aging dynamics. This kind of discrimination study is very original and unique for the literature. The schematic seen in Figure 3 summarizes the flow of the study and in Figure 4 the pseudo code is presented.

Authors have presented a KF fusion study with current signals [41]. The SV is executed using statistical analysis while FD is done through the spectral analysis. The current signal's deterministic nature does not permit any further interpretation like aging or the determination of health status for the system. However, in this study, through the stochastic nature of vibration signals, Kalman algorithm provides more information to use different tools. Statistical, spectral investigations are supported with coherences to succeed SV and FD. Additionally, discrimination of process problems and aging becomes possible by the defining a rate representing healthiness.

\subsection{Sensor validation and fault detection through data fusion supported by Kalman filter}

The purpose of this section, revealing the sensor performance and to detect the aging while one or all sensors are damaged. In other words, SV and FD are achieved together. For this aim, various measurement noises are applied to sensors for different aging cycles. In addition, FD is supported by the sensor fusion algorithm which is empowered by KF. The flow for the method is illustrated step by step in Figure 5.

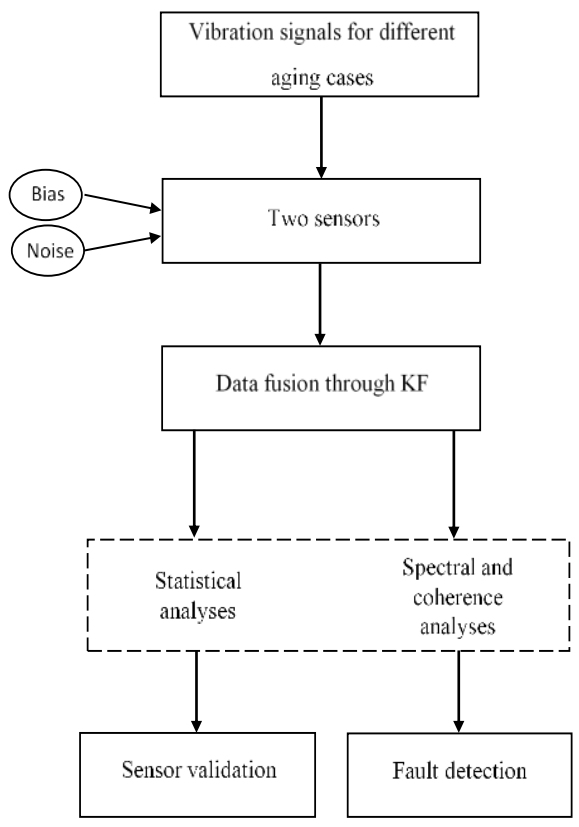

Figure 5. DF through KF algorithm for FD and SV applications
In fusion algorithm, the original signal $(x)$ can be obtained from sensors with or without noise. Regarding Eq. (9), the fused signal is $x_{f}$ while the first and second sensor information are $x_{1}$ and $x_{2}$. In order to create the process and measurement noises, authors assume that there are two sensors with duplicated information including deformations such as offsets or unexpected phase differences and biases. According to the proposed method, the outputs of the sensors; $\boldsymbol{x}_{\boldsymbol{t} 1}, \boldsymbol{x}_{\boldsymbol{t} 2}$ are fused together by KF supported FD algorithm. Thereupon, FD is actualized by evaluating the statistical and spectral properties of the fused signal $\boldsymbol{x}_{\boldsymbol{f}}$ and the sensor outputs.

For fusion algorithm, two vibration sensors with measurement noises (as biases $+b$ and $-b$ ) are considered. Then, the fused signal $\boldsymbol{x}_{\boldsymbol{f}}$, which is assumed to estimate the original signal, is obtained through fusion algorithm. Three different scenarios are planned to be applied on vibration signals for each cycle. Scenarios and their aims are given in Table 2.

Each scenario is executed for the first (healthy case), third and seventh aging cycles (aged case). Statistical and spectral results of them are investigated.

Tables 3, 4 and 5 present the statistical analysis of the collected and the fused signals for three different aging cycles respectively. In these tables, $\mathbf{Q}$ represents the process noise, while $\boldsymbol{R}_{\boldsymbol{I}}$ and $\boldsymbol{R}_{\boldsymbol{2}}$ represent the measurement noises which associate Sensor 1 and Sensor 2, respectively. Furthermore, $\boldsymbol{M S E _ { 1 }}$ and $\boldsymbol{M S E _ { 2 }}$ are mean square errors, $\boldsymbol{R M} \boldsymbol{S}_{1}$ and $\boldsymbol{R M} \boldsymbol{S}_{2}$ are root mean square error between fused signal and the output of the sensor 1 and 2, respectively. In the tables below, $\operatorname{std} x_{1}, \operatorname{std} x_{2}, \operatorname{std} x_{f}$ are standard deviations; $M \boldsymbol{x}_{1}, M \boldsymbol{x}_{2}$, $M \boldsymbol{x}_{f}$ are mean values; Kurt $\boldsymbol{x}_{1}$, Kurt $\boldsymbol{x}_{2}$, Kurt $\boldsymbol{x}_{f}$ are kurtoses of $\boldsymbol{x}_{1}, \boldsymbol{x}_{2}$ and $\boldsymbol{x}_{f}$, respectively. $\boldsymbol{K}_{x 1}$ and $\boldsymbol{K}_{x 2}$ are Kalman gain of the first and the second sensor, respectively. In these tables Test \#0 is supposed as the reference test associated with a system with minimum measurement and process noises.

First and second scenarios are applied to the data and given in Tables 3, 4 and 5. When the measurement noises of two sensors are increased equally, the error values remain constant even in third and seventh aging cycles. Moreover, the Kalman gains $(\mathrm{KG})$ for the sensors decrease with higher measurement noises.

In the second part of the tables, which present the results of the second scenario, it is assumed that only one of the sensors is faulty. The mean values of the fused signal converge to the signal which is obtained from the healthy sensor. Furthermore, the standard deviation of the fused signal remains constant because the algorithm eliminates the faulty sensor. However, the kurtosis scales up, while, the difference between the noises of the sensors increment. In addition, the $\mathrm{KG}$ of the faulty sensor decreases distinctly. According to the tables, monitoring $\mathrm{KG}$ is very useful for detecting measurement noises. However, by the aging of the system KG does not alter, hence, it is not suitable for neither aging detection nor FD.

Table 2. Detailed information on the scenarios

\begin{tabular}{cccc}
\hline Scenarios & Simulation Aim & Definition & Action \\
\hline $\mathbf{1}^{\text {st }}$ & Measurement problems & Faulty (noisy) sensor outputs are dealt. & The measurement noise of all sensors is \\
$\mathbf{2}^{\text {nd }}$ & Sensor problems & Only one of the sensors is assumed to be faulty. & $\begin{array}{c}\text { The measurement noise of one sensor is } \\
\text { increased only. }\end{array}$ \\
$\mathbf{3}^{\text {rd }}$ & Faulty process (Aging) & The noise is originated from the process (either & The measurement noise is kept minimum \\
& & electrical or mechanical) & while the process noise is increased. \\
\hline
\end{tabular}


Table 3. Statistical properties of the first aging cycle (healthy case) vibration signal under measurement noises

\begin{tabular}{|c|c|c|c|c|c|c|c|c|c|c|c|c|c|c|c|c|c|c|}
\hline Test & $\boldsymbol{R}_{1}$ & $\boldsymbol{R}_{2}$ & $\mathbf{Q}$ & $K x_{1}$ & $K x_{2}$ & $M S E_{1}$ & $M S E_{2}$ & $R M S_{I}$ & $R M S_{2}$ & $\begin{array}{c}S t d \\
x_{1}\end{array}$ & $\begin{array}{c}S t d \\
x_{2}\end{array}$ & $\begin{array}{c}S t d \\
x_{f}\end{array}$ & $\begin{array}{l}M \\
x_{1}\end{array}$ & $\begin{array}{l}M \\
x_{2}\end{array}$ & $\begin{array}{l}M \\
x_{f} \\
\end{array}$ & $\begin{array}{c}\text { Kurt } \\
x_{1}\end{array}$ & $\begin{array}{c}\text { Kurt } \\
x_{2}\end{array}$ & $\begin{array}{c}\text { Kurt } \\
x_{f}\end{array}$ \\
\hline \multicolumn{19}{|c|}{$1^{\text {st }}$ Scenario } \\
\hline$\# 0$ & 0.01 & 0.01 & 0.005 & 0.31 & 0.31 & 25 & 25 & 5 & 5 & 0.17 & 0.17 & 0.12 & 5 & -5 & 0 & 3 & 3 & 3 \\
\hline$\# 1$ & 0.02 & 0.02 & 0.005 & 0.25 & 0.25 & 25 & 25 & 5 & 5 & 0.19 & 0.19 & 0.12 & 5 & -5 & 0 & 3 & 3 & 3 \\
\hline$\# 2$ & 0.04 & 0.04 & 0.005 & 0.19 & 0.19 & 25 & 25 & 5 & 5 & 0.24 & 0.24 & 0.12 & 5 & -5 & 0 & 3 & 3 & 3 \\
\hline \#3 & 0.08 & 0.08 & 0.005 & 0.15 & 0.15 & 25 & 25 & 5 & 5 & 0.31 & 0.31 & 0.12 & 5 & -5 & 0 & 3 & 3 & 3 \\
\hline \#4 & 0.16 & 0.16 & 0.005 & 0.11 & 0.11 & 25.14 & 25.14 & 5 & 5 & 0.42 & 0.42 & 0.12 & 5 & -5 & 0 & 3 & 3 & 3 \\
\hline$\# 5$ & 0.32 & 0.32 & 0.005 & 0.081 & 0.081 & 25.3 & 25.3 & 5 & 5 & 0.58 & 0.58 & 0.13 & 5 & -5 & 0 & 3 & 3 & 3 \\
\hline \#6 & 0.64 & 0.64 & 0.005 & 0.058 & 0.058 & 25.6 & 25.6 & 5 & 5 & 0.81 & 0.81 & 0.15 & 5 & -5 & 0 & 3 & 3 & 3 \\
\hline$\# 7$ & 1 & 1 & 0.005 & 0.048 & 0.048 & 25.9 & 25.9 & 5.1 & 5.1 & 1 & 1 & 0.16 & 5 & -5 & 0 & 3 & 3 & 3 \\
\hline \multicolumn{19}{|c|}{$2^{\text {nd }}$ Scenario } \\
\hline$\# 8$ & 0.1 & 0.005 & 0.001 & 0.017 & 0.35 & 90.7 & 0.23 & 9.5 & 0.5 & 0.34 & 0.14 & 0.093 & 5 & -5 & - & 3 & 3 & 107 \\
\hline$\# 9$ & 0.5 & 0.005 & 0.001 & 0.004 & 0.356 & 98.5 & 0.017 & 9.93 & 0.13 & 0.72 & 0.14 & 0.093 & 5 & -5 & -5 & 3 & 3 & 139 \\
\hline$\# 10$ & 1 & 0.005 & 0.001 & 0.002 & 0.357 & 100 & 0.01 & 10 & 0.1 & 1 & 0.14 & 0.093 & 5 & -5 & -5 & 3 & 3 & 143 \\
\hline \#11 & 0.005 & 0.1 & 0.001 & 0.347 & 0.017 & 0.23 & 90.8 & 0.5 & 9.5 & 0.14 & 0.34 & 0.093 & 5 & -5 & 4.5 & 3 & 3 & 20 \\
\hline \#12 & 0.01 & 0.2 & 0.001 & 0.263 & 0.013 & 0.24 & 90.85 & 0.5 & 9.5 & 0.15 & 0.46 & 0.084 & 5 & -5 & 4.5 & 3 & 3 & 28 \\
\hline \#13 & 0.01 & 0.4 & 0.001 & 0.266 & 0.007 & 0.072 & 95.5 & 0.27 & 0.97 & 0.15 & 0.64 & 0.084 & 5 & -5 & 4.7 & 3 & 3 & 35.8 \\
\hline
\end{tabular}

Table 4. Statistical properties of the third aging cycle vibration signal under measurement noises

\begin{tabular}{|c|c|c|c|c|c|c|c|c|c|c|c|c|c|c|c|c|c|c|}
\hline Test & $R_{1}$ & $R_{2}$ & $\mathbf{Q}$ & $K x_{1}$ & $K x_{2}$ & $\overline{M S E_{1}}$ & $\overline{M S E_{2}}$ & $R M S_{1}$ & $R_{R M S_{2}}$ & $\begin{array}{c}\text { Std } \\
x_{1}\end{array}$ & $\begin{array}{c}S t d \\
x_{2} \\
\end{array}$ & $\begin{array}{c}S t d \\
x_{f}\end{array}$ & $\begin{array}{l}M \\
x_{1}\end{array}$ & $\begin{array}{l}M \\
x_{2} \\
\end{array}$ & $\begin{array}{l}M \\
x_{f}\end{array}$ & $\begin{array}{c}\text { Kurt } \\
x_{1}\end{array}$ & $\begin{array}{c}\text { Kurt } \\
x_{2}\end{array}$ & $\begin{array}{c}\text { Kurt } \\
x_{f}\end{array}$ \\
\hline \multicolumn{19}{|c|}{$1^{\text {st }}$ scenario } \\
\hline$\# 0$ & 0.01 & 0.01 & 0.005 & 0.31 & 0.31 & 25 & 25 & 5 & 5 & 0.31 & 0.31 & 0.23 & 5 & -5 & 0 & 3 & 3 & 3 \\
\hline$\# 1$ & 0.02 & 0.02 & 0.005 & 0.25 & 0.25 & 25 & 25 & 5 & 5 & 0.33 & 0.33 & 0.2 & 5 & -5 & 0 & 3 & 3 & 3 \\
\hline \#2 & 0.04 & 0.04 & 0.005 & 0.19 & 0.19 & 25 & 25 & 5 & 5 & 0.36 & 0.36 & 0.18 & 5 & -5 & 0 & 3 & 3 & 3 \\
\hline \#3 & 0.08 & 0.08 & 0.005 & 0.15 & 0.15 & 25 & 25 & 5 & 5 & 0.41 & 0.41 & 0.16 & 5 & -5 & 0 & 3 & 3 & 3 \\
\hline \#4 & 0.16 & 0.16 & 0.005 & 0.11 & 0.11 & 25.2 & 25.2 & 5 & 5 & 0.5 & 0.5 & 0.15 & 5 & -5 & 0 & 3 & 3 & 3 \\
\hline$\# 5$ & 0.32 & 0.32 & 0.005 & 0.081 & 0.081 & 25.35 & 25.35 & 5 & 5 & 0.64 & 0.64 & 0.15 & 5 & -5 & 0 & 3 & 3 & 3 \\
\hline \#6 & 0.64 & 0.64 & 0.005 & 0.058 & 0.058 & 25.7 & 25.7 & 5 & 5 & 0.85 & 0.85 & 0.16 & 5 & -5 & 0 & 3 & 3 & 3 \\
\hline$\# 7$ & 1 & 1 & 0.005 & 0.048 & 0.048 & 25.9 & 25.9 & 5.1 & 5.1 & 1 & 1 & 0.17 & 5 & -5 & 0 & 3 & 3 & 3 \\
\hline \multicolumn{19}{|c|}{$2^{\text {nd }}$ scenario } \\
\hline$\# 8$ & 0.1 & 0.005 & 0.001 & 0.017 & 0.35 & 90.84 & 0.27 & 9.5 & 0.5 & 0.43 & 0.3 & 0.16 & 5 & -5 & $\overline{4}$ & 3 & 3 & 14.6 \\
\hline$\# 9$ & 0.5 & 0.005 & 0.001 & 0.004 & 0.356 & 98.5 & 0.052 & 9.9 & 0.23 & 0.76 & 0.3 & 0.16 & 5 & -5 & - & 3 & 3 & 18.8 \\
\hline$\# 10$ & 1 & 0.005 & 0.001 & 0.002 & 0.357 & 100 & 0.044 & 10 & 0.2 & 1 & 0.3 & 0.16 & 5 & -5 & -5 & 3 & 3 & 19.4 \\
\hline \#11 & 0.005 & 0.1 & 0.001 & 0.347 & 0.017 & 0.27 & 90.84 & 0.5 & 9.5 & 0.3 & 0.43 & 0.16 & 5 & -5 & 4.5 & 3 & 3 & 4.8 \\
\hline$\# 12$ & 0.01 & 0.2 & 0.001 & 0.263 & 0.013 & 0.28 & 90.9 & 0.5 & 9.5 & 0.31 & 0.53 & 0.13 & 5 & -5 & 4.5 & 3 & 3 & 7 \\
\hline$\# 13$ & 0.01 & 0.4 & 0.001 & 0.266 & 0.007 & 0.12 & 95.66 & 0.34 & 9.8 & 0.31 & 0.7 & 0.13 & 5 & -5 & 4.7 & 3 & 3 & 8 \\
\hline
\end{tabular}

Table 5. Statistical properties of the seventh aging cycle (aged case) vibration signal under measurement noises

\begin{tabular}{|c|c|c|c|c|c|c|c|c|c|c|c|c|c|c|c|c|c|c|}
\hline Test & $R_{I}$ & $R_{2}$ & $\mathbf{Q}$ & $K x_{1}$ & $K x_{2}$ & $M S E_{1}$ & $M S E_{2}$ & $R M S_{1}$ & $R M S_{2}$ & $\begin{array}{c}\text { Std } \\
x_{1}\end{array}$ & $\begin{array}{c}\text { Std } \\
x_{2}\end{array}$ & $\begin{array}{c}S t d \\
x_{f}\end{array}$ & $\begin{array}{l}M \\
x_{I} \\
\end{array}$ & $\begin{array}{l}M \\
x_{2} \\
\end{array}$ & $\begin{array}{c}M \\
x_{f} \\
\end{array}$ & $\begin{array}{c}\text { Kurt } \\
x_{I}\end{array}$ & $\begin{array}{c}\text { Kurt } \\
x_{2}\end{array}$ & $\begin{array}{c}\text { Kurt } \\
x_{f}\end{array}$ \\
\hline \multicolumn{19}{|c|}{$1^{\text {st }}$ scenario } \\
\hline$\# 0$ & 0.01 & 0.01 & 0.005 & 0.31 & 0.31 & 25 & 25 & 5 & 5 & 0.62 & 0.62 & 0.38 & 5 & -5 & 0 & 3 & 3 & 3 \\
\hline$\# 1$ & 0.02 & 0.02 & 0.005 & 0.25 & 0.25 & 25.15 & 25.15 & 5 & 5 & 0.62 & 0.62 & 0.32 & 5 & -5 & 0 & 3 & 3 & 3 \\
\hline \#2 & 0.04 & 0.04 & 0.005 & 0.19 & 0.19 & 25.22 & 25.22 & 5 & 5 & 0.64 & 0.64 & 0.26 & 5 & -5 & 0 & 3 & 3 & 3 \\
\hline$\# 3$ & 0.08 & 0.08 & 0.005 & 0.15 & 0.15 & 25.3 & 25.3 & 5 & 5 & 0.67 & 0.67 & 0.21 & 5 & -5 & 0 & 3 & 3 & 3 \\
\hline \#4 & 0.16 & 0.16 & 0.005 & 0.11 & 0.11 & 25.4 & 25.4 & 5 & 5 & 0.73 & 0.73 & 0.18 & 5 & -5 & 0 & 3 & 3 & 3 \\
\hline$\# 5$ & 0.32 & 0.32 & 0.005 & 0.081 & 0.081 & 25.6 & 25.6 & 5 & 5 & 0.83 & 0.83 & 0.16 & 5 & -5 & 0 & 3 & 3 & 3 \\
\hline$\# 6$ & 0.64 & 0.64 & 0.005 & 0.058 & 0.058 & 25.8 & 25.8 & 5 & 5 & 1 & 1 & 0.16 & 5 & -5 & 0 & 3 & 3 & 3 \\
\hline \#7 & 1 & 1 & 0.005 & 0.048 & 0.048 & 26.25 & 26.25 & 5.12 & 5.12 & 1.17 & 1.17 & 0.17 & 5 & -5 & 0 & 3 & 3 & 3 \\
\hline \multicolumn{19}{|c|}{$2^{\text {nd }}$ scenario } \\
\hline$\# 8$ & 0.1 & 0.005 & 0.001 & 0.017 & 0.35 & 90.99 & 0.43 & 9.5 & 0.65 & 0.68 & 0.61 & 0.23 & 5 & -5 & -4.5 & 3 & 3 & 5.47 \\
\hline$\# 9$ & 0.5 & 0.005 & 0.001 & 0.004 & 0.356 & 98.74 & 0.2 & 9.94 & 0.46 & 0.93 & 0.61 & 0.23 & 5 & -5 & -4.9 & 3 & 3 & 6.4 \\
\hline$\# 10$ & 1 & 0.005 & 0.001 & 0.002 & 0.357 & 100.13 & 0.2045 & 10 & 0.45 & 1.17 & 0.61 & 0.23 & 5 & -5 & -4.9 & 3 & 3 & 6.7 \\
\hline$\# 11$ & 0.005 & 0.1 & 0.001 & 0.347 & 0.017 & 0.43 & 91 & 0.65 & 9.5 & 0.61 & 0.68 & 0.24 & 5 & -5 & 4.5 & 3 & 3 & 3.4 \\
\hline$\# 12$ & 0.01 & 0.2 & 0.001 & 0.263 & 0.013 & 0.47 & 91.10 & 0.7 & 9.5 & 0.61 & 0.75 & 0.18 & 5 & -5 & 4.5 & 3 & 3 & 4 \\
\hline$\# 13$ & 0.01 & 0.4 & 0.001 & 0.266 & 0.007 & 0.31 & 95.84 & 0.56 & 9.8 & 0.6 & 0.87 & 0.18 & 5 & -5 & 4.76 & 3 & 3 & 4.46 \\
\hline
\end{tabular}

The spectral density results and coherences (Figures 6-11) illustrates more supporting features. Note that, Test \#0 in Table 3 is the reference test for healthy system ( $1^{\text {st }}$ cycle). It does not contain significant amount of measurement and process noises. Figures 6 and 7 are the reference figures for spectral representation of each aging cycle. They demonstrate the ability on estimating dominant frequencies of the proposed sensor fusion application.

Figure 8(c) and Figures 10(b-c) clearly demonstrate that, in spite of the defected sensors, the fused signal is able to detect the aging indications which are noticeable between $2-4 \mathrm{kHz}$. Moreover, as a result of Kalman algorithm filtering characteristics, the data fusion supported by KF can eliminate the faulty sensor. Thus, the faulty sensor becomes distinguishable. As regards, when only one of the sensors is damaged or faulty (Figure 10), the fused signal converges to the original signal and calculating an accurate estimation.

In order to support spectral findings, coherences between 
the fused signal and the original signals are also shared in Figures 8 and 11 for different tests. According to the Figures 8 and 11, when the system is aged, the coherence of the fused signal with the original one grows in the $2-4 \mathrm{kHz}$ frequency range. In addition, when all of the sensors are damaged (Figure $9)$, the coherence decrease in the lower frequency range.

As a consequence, in spite of the existence of the faulty sensors, the source of the faults (either one sensor or all sensors) can be easily identified. Thus, the SV is executed very successfully. Moreover, since the KF fusion algorithm imitates the frequency components between 2-4 kHz, FD can be performed simply. To sum up, the outputs of the spectral and the statistical analyses justify each other.

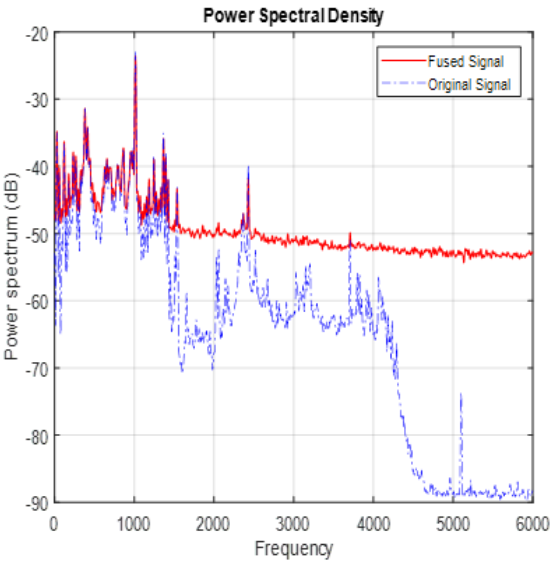

(a) Healthy Condition

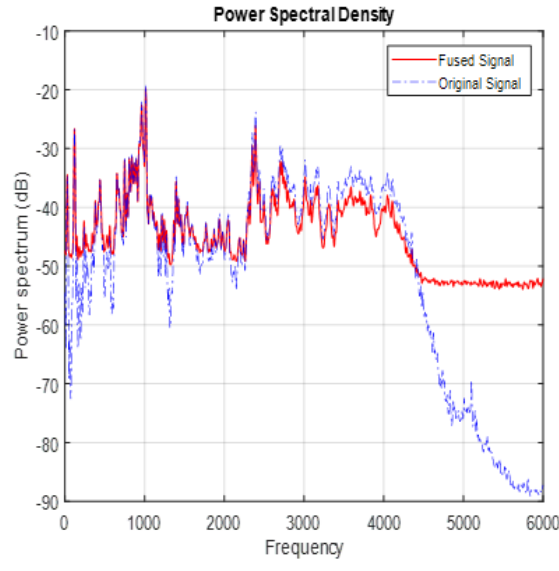

(b) Third Cycle

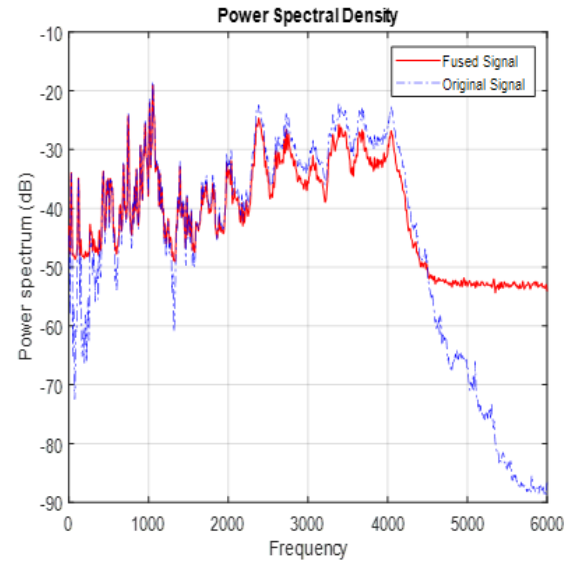

(c) Seventh Cycle

Figure 6. Spectral results of Test $\# 0$ (The reference test) for different aging cycles

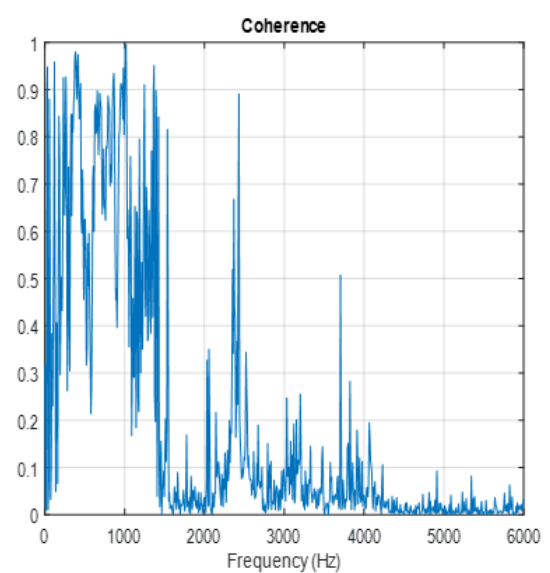

(a) Healthy Condition

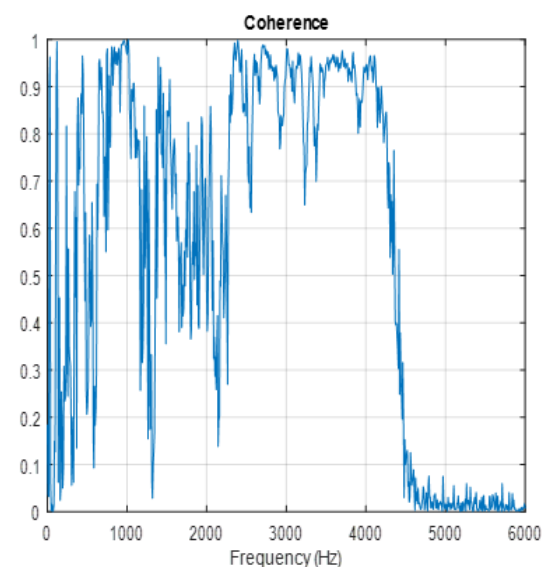

(b) Third Cycle

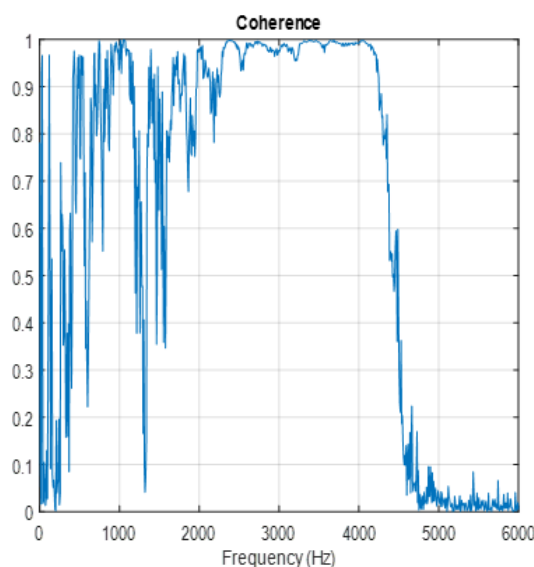

(c) Seventh Cycle

Figure 7. Coherences of the reference test for different aging cycles

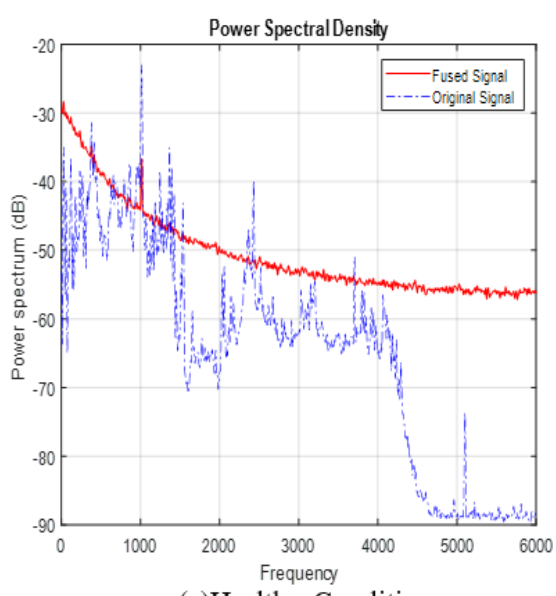

(a)Healthy Condition

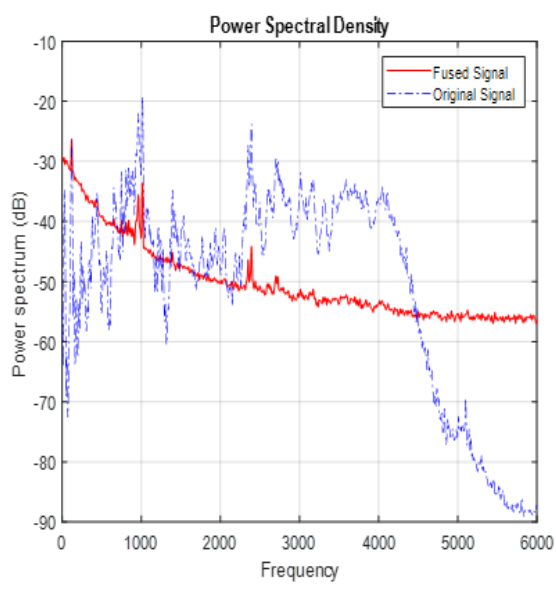

(b) Third Cycle

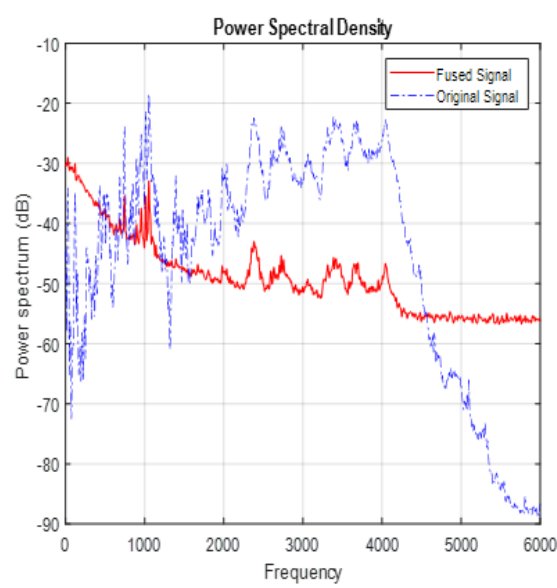

(b) Seventh Cycle

Figure 8. Spectral results of Test \#7 


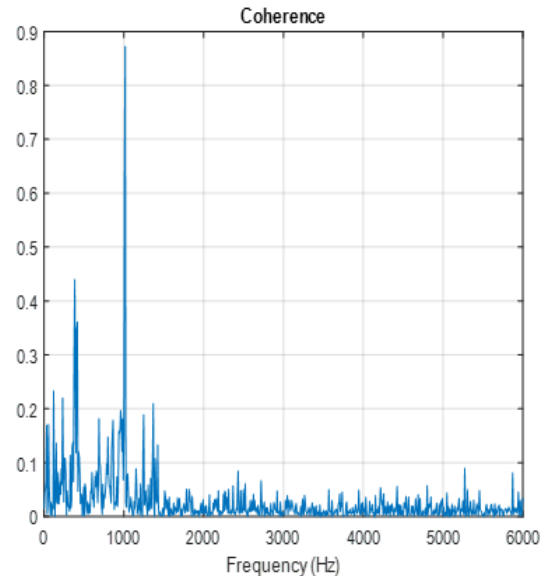

(a)Healthy Condition

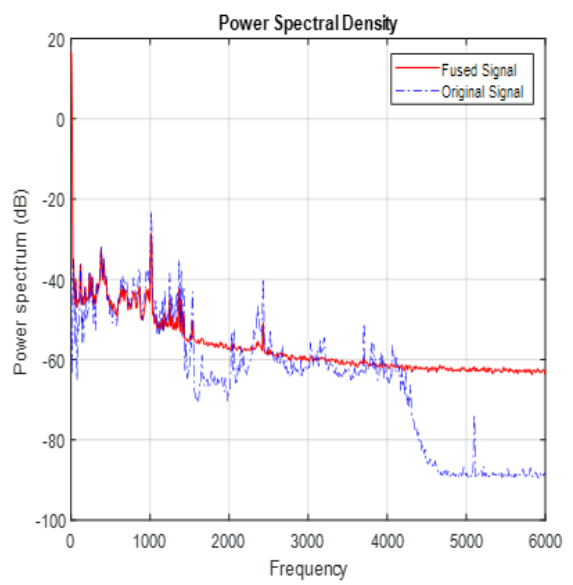

(a) Healthy Condition

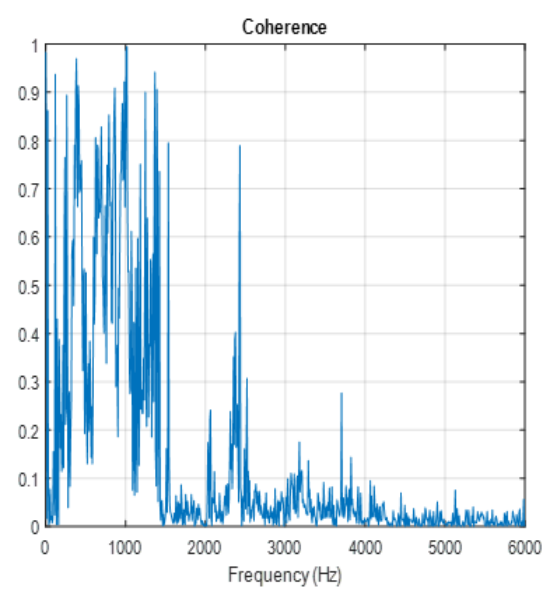

(a)Healthy Condition

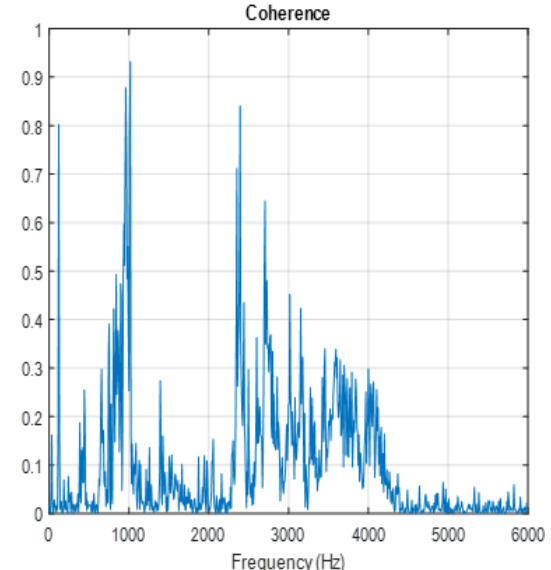

(b) Third Cycle

Figure 9. Coherences of Test \#7

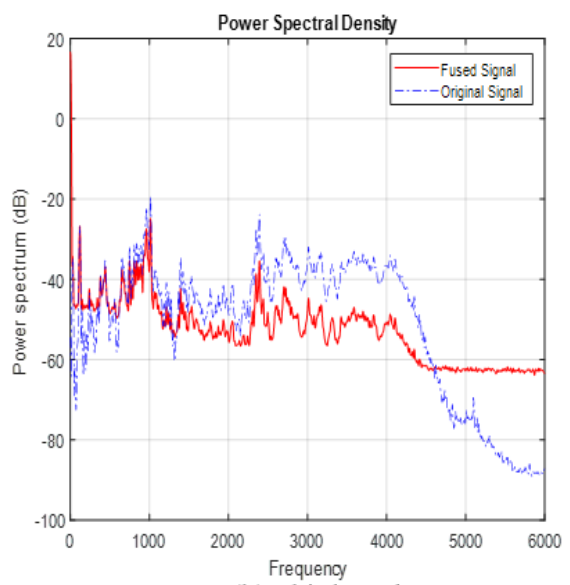

(b) Third Cycle

Figure 10. Spectral results of Test \#13

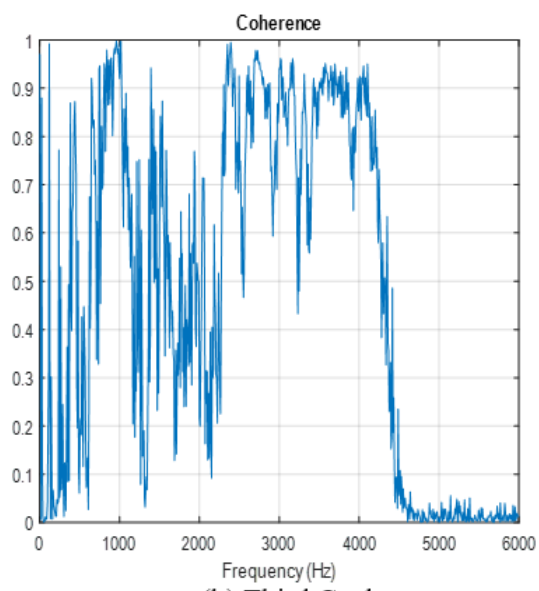

(b) Third Cycle

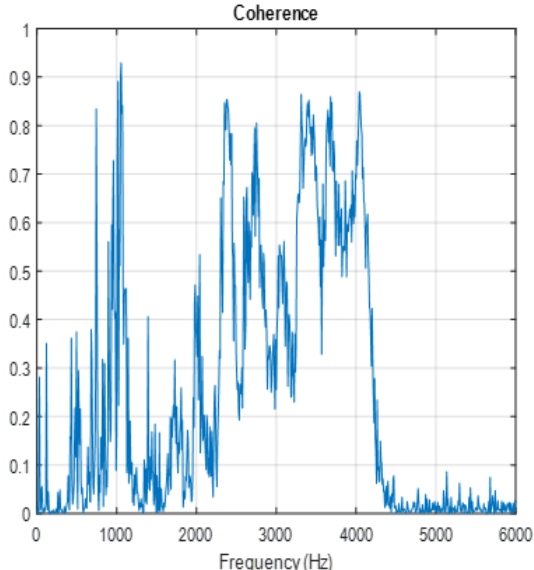

(c) Seventh Cycle

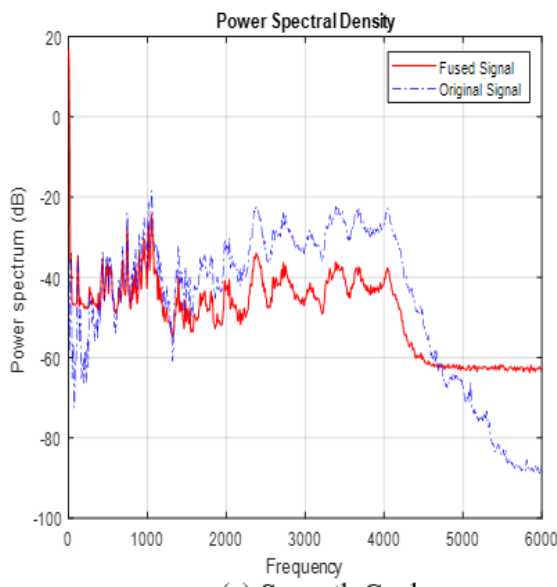

(c) Seventh Cycle

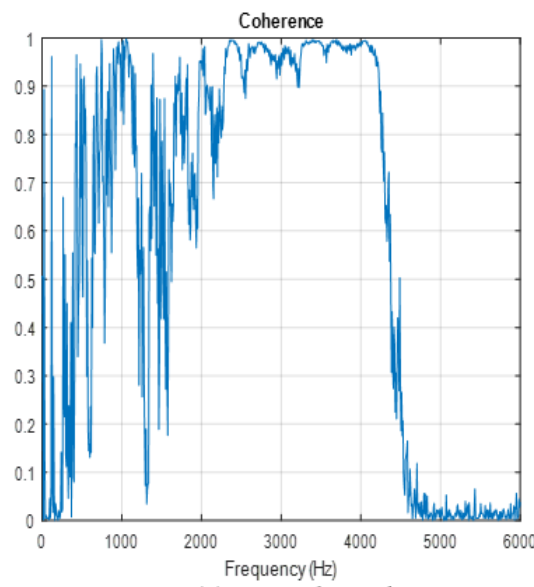

(c) Seventh Cycle

Figure 11. Coherences for Test \#13

\subsection{Fault detection under severe process noise}

In the third scenario, in order to observe the effect of the process noise, authors apply various process noises for each aging cycle. The statistical and spectral results related to the healthy condition, third and seventh cycles are presented here also under the impact of process noise.

Tables 6-8 demonstrate that the process noise $(\boldsymbol{Q})$ has a significant effect on the standard deviations of the measured signals and the fused signal. Process noise influences similarly on the both sensors and the fused signal. Consequently, the errors remain constant while the standard deviation increases equally. Moreover, impact of aging is detectable on the standard deviation values. Under the significant process noise, the Kalman gain of all sensors saturate to the same value $(0.5)$.

Figures 12 and 13 illustrate the spectral and coherence analyses, respectively. The fused signal does not show any information expect for the very dominant frequency 
components for different aging cycles, as seen in Figure 13. There exists some limited information about aging in seventh cycle since these components are dominant. However, if the process noise increases more and more, the information about the aging which exist in the fused signal, is vanished. Figure 13 represents a better perspective about the fault component of the system (aging indications). The amplitude of the frequency components between $2-4 \mathrm{KHz}$ increases. Consequently, the fault is detected through coherences, while the process noise is dominant. Nevertheless, to obtain a relationship between the process noises and the aging cycles, a health information is proposed in the next section.

Table 6. Statistical properties of the first aging cycle (healthy case) vibration signal under process noise

\begin{tabular}{|c|c|c|c|c|c|c|c|c|c|c|c|c|c|c|c|c|c|c|}
\hline Test & $R_{1}$ & $R_{2}$ & $\mathbf{Q}$ & $K x_{I}$ & $K x_{2}$ & $M S E_{1}$ & $M S E_{2}$ & $R M S_{1}$ & $R M S_{2}$ & $\begin{array}{c}S t d \\
x_{1}\end{array}$ & $\begin{array}{c}S t d \\
x_{2}\end{array}$ & $\begin{array}{c}S t d \\
x_{f}\end{array}$ & $\begin{array}{l}M \\
x_{1} \\
\end{array}$ & $\begin{array}{l}M \\
x_{2} \\
\end{array}$ & $\begin{array}{c}M \\
x_{f}\end{array}$ & $\begin{array}{c}\text { Kurt } \\
x_{1}\end{array}$ & $\begin{array}{c}\text { Kurt } \\
x_{2}\end{array}$ & $\begin{array}{c}\text { Kurt } \\
x_{f}\end{array}$ \\
\hline$\# 1$ & 0.005 & 0.005 & 0.005 & 0.36 & 0.36 & 25 & 25 & 5 & 5 & 0.15 & 0.15 & 0.12 & 5 & -5 & 0 & 3 & 3 & 3 \\
\hline$\# 2$ & 0.005 & 0.005 & 0.01 & 0.41 & 0.41 & 25 & 25 & 5 & 5 & 0.17 & 0.17 & 0.14 & 5 & -5 & 0 & 3 & 3 & 3 \\
\hline$\# 3$ & 0.005 & 0.005 & 0.02 & 0.44 & 0.44 & 25 & 25 & 5 & 5 & 0.19 & 0.19 & 0.17 & 5 & -5 & 0 & 3 & 3 & 3 \\
\hline \#4 & 0.005 & 0.005 & 0.04 & 0.47 & 0.47 & 25 & 25 & 5 & 5 & 0.24 & 0.24 & 0.22 & 5 & -5 & 0 & 3 & 3 & 3 \\
\hline$\# 5$ & 0.005 & 0.005 & 0.08 & 0.48 & 0.48 & 25 & 25 & 5 & 5 & 0.31 & 0.31 & 0.30 & 5 & -5 & 0 & 3 & 3 & 3 \\
\hline$\# 6$ & 0.005 & 0.005 & 0.16 & 0.492 & 0.492 & 25 & 25 & 5 & 5 & 0.42 & 0.42 & 0.41 & 5 & -5 & 0 & 3 & 3 & 3 \\
\hline$\# 7$ & 0.005 & 0.005 & 0.32 & 0.496 & 0.496 & 25 & 25 & 5 & 5 & 0.58 & 0.58 & 0.57 & 5 & -5 & 0 & 3 & 3 & 3 \\
\hline \#8 & 0.005 & 0.005 & 0.64 & 0.498 & 0.498 & 25 & 25 & 5 & 5 & 0.81 & 0.81 & 0.81 & 5 & -5 & 0 & 3 & 3 & 3 \\
\hline \#9 & 0.005 & 0.005 & 1 & 0.498 & 0.498 & 25 & 25 & 5 & 5 & 1 & 1 & 1 & 5 & -5 & 0 & 3 & 3 & 3 \\
\hline
\end{tabular}

Table 7. Statistical properties of the third aging cycle vibration signal under process noise

\begin{tabular}{|c|c|c|c|c|c|c|c|c|c|c|c|c|c|c|c|c|c|c|}
\hline Test & $R_{1}$ & $R_{2}$ & $\mathbf{Q}$ & $K x_{1}$ & $K x_{2}$ & $M S E_{1}$ & $M S E_{2}$ & $\boldsymbol{R} M \boldsymbol{S}_{I}$ & $R M S_{2}$ & $\begin{array}{c}S t d \\
x_{1} \\
\end{array}$ & $\begin{array}{c}\text { Std } \\
x_{2} \\
\end{array}$ & $\begin{array}{c}S t d \\
x_{f} \\
\end{array}$ & $\begin{array}{l}M \\
x_{1} \\
\end{array}$ & $\begin{array}{l}M \\
x_{2} \\
\end{array}$ & $\begin{array}{r}M \\
x_{f} \\
\end{array}$ & $\begin{array}{c}\text { Kurt } \\
x_{1} \\
\end{array}$ & $\begin{array}{c}\text { Kurt } \\
x_{2} \\
\end{array}$ & $\begin{array}{c}\text { Kurt } \\
x_{f} \\
\end{array}$ \\
\hline$\# 1$ & 0.005 & 0.005 & 0.005 & 0.36 & 0.36 & 25 & 25 & 5 & 5 & 0.3 & 0.3 & 0.25 & 5 & -5 & 0 & 3 & 3 & 3 \\
\hline$\# 2$ & 0.005 & 0.005 & 0.01 & 0.41 & 0.41 & 25 & 25 & 5 & 5 & 0.31 & 0.31 & 0.27 & 5 & -5 & 0 & 3 & 3 & 3 \\
\hline$\# 3$ & 0.005 & 0.005 & 0.02 & 0.44 & 0.44 & 25 & 25 & 5 & 5 & 0.33 & 0.33 & 0.3 & 5 & -5 & 0 & 3 & 3 & 3 \\
\hline$\# 4$ & 0.005 & 0.005 & 0.04 & 0.47 & 0.47 & 25 & 25 & 5 & 5 & 0.36 & 0.36 & 0.34 & 5 & -5 & 0 & 3 & 3 & 3 \\
\hline$\# 5$ & 0.005 & 0.005 & 0.08 & 0.48 & 0.48 & 25 & 25 & 5 & 5 & 0.41 & 0.41 & 0.4 & 5 & -5 & 0 & 3 & 3 & 3 \\
\hline \#6 & 0.005 & 0.005 & 0.16 & 0.492 & 0.492 & 25 & 25 & 5 & 5 & 0.5 & 0.5 & 0.49 & 5 & -5 & 0 & 3 & 3 & 3 \\
\hline \#7 & 0.005 & 0.005 & 0.32 & 0.496 & 0.496 & 25 & 25 & 5 & 5 & 0.64 & 0.64 & 0.63 & 5 & -5 & 0 & 3 & 3 & 3 \\
\hline$\# 8$ & 0.005 & 0.005 & 0.64 & 0.498 & 0.498 & 25 & 25 & 5 & 5 & 0.85 & 0.85 & 0.85 & 5 & -5 & 0 & 3 & 3 & 3 \\
\hline$\# 9$ & 0.005 & 0.005 & 1 & 0.498 & 0.498 & 25 & 25 & 5 & 5 & 1.04 & 1.04 & 1.04 & 5 & -5 & 0 & 3 & 3 & 3 \\
\hline
\end{tabular}

Table 8. Statistical properties of the seventh aging cycle vibration signal under process noise

\begin{tabular}{|c|c|c|c|c|c|c|c|c|c|c|c|c|c|c|c|c|c|c|}
\hline Test & $R_{1}$ & $R_{2}$ & $\mathbf{Q}$ & $K x_{1}$ & $K x_{2}$ & $M S E_{1}$ & $M S E_{2}$ & $R M S_{1}$ & $R M S_{2}$ & $\begin{array}{c}S t d \\
x_{1}\end{array}$ & $\begin{array}{c}S t d \\
x_{2}\end{array}$ & $\begin{array}{c}S t d \\
x_{f}\end{array}$ & $\begin{array}{l}M \\
x_{1}\end{array}$ & $\begin{array}{l}M \\
x_{2}\end{array}$ & $\begin{array}{l}M \\
x_{f}\end{array}$ & $\begin{array}{c}\text { Kurt } \\
x_{1}\end{array}$ & $\begin{array}{c}\text { Kurt } \\
x_{2}\end{array}$ & $\begin{array}{c}\text { Kurt } \\
x_{f}\end{array}$ \\
\hline$\# 1$ & 0.005 & 0.005 & 0.005 & 0.36 & 0.36 & 25 & 25 & 5 & 5 & 0.6 & 0.6 & 0.4 & 5 & -5 & 0 & 3 & 3 & 3 \\
\hline$\# 2$ & 0.005 & 0.005 & 0.01 & 0.41 & 0.41 & 25 & 25 & 5 & 5 & 0.62 & 0.62 & 0.51 & 5 & -5 & 0 & 3 & 3 & 3 \\
\hline \#3 & 0.005 & 0.005 & 0.02 & 0.44 & 0.44 & 25 & 25 & 5 & 5 & 0.62 & 0.62 & 0.56 & 5 & -5 & 0 & 3 & 3 & 3 \\
\hline$\# 4$ & 0.005 & 0.005 & 0.04 & 0.47 & 0.47 & 25 & 25 & 5 & 5 & 0.64 & 0.64 & 0.60 & 5 & -5 & 0 & 3 & 3 & 3 \\
\hline$\# 5$ & 0.005 & 0.005 & 0.08 & 0.48 & 0.48 & 25 & 25 & 5 & 5 & 0.67 & 0.67 & 0.65 & 5 & -5 & 0 & 3 & 3 & 3 \\
\hline \#6 & 0.005 & 0.005 & 0.16 & 0.492 & 0.492 & 25 & 25 & 5 & 5 & 0.73 & 0.73 & 0.71 & 5 & -5 & 0 & 3 & 3 & 3 \\
\hline$\# 7$ & 0.005 & 0.005 & 0.32 & 0.496 & 0.496 & 25 & 25 & 5 & 5 & 0.83 & 0.83 & 0.82 & 5 & -5 & 0 & 3 & 3 & 3 \\
\hline$\# 8$ & 0.005 & 0.005 & 0.64 & 0.498 & 0.498 & 25 & 25 & 5 & 5 & 1 & 1 & 1 & 5 & -5 & 0 & 3 & 3 & 3 \\
\hline$\# 9$ & 0.005 & 0.005 & 1 & 0.498 & 0.498 & 25 & 25 & 5 & 5 & 1.17 & 1.17 & 1.16 & 5 & -5 & 0 & 3 & 3 & 3 \\
\hline
\end{tabular}

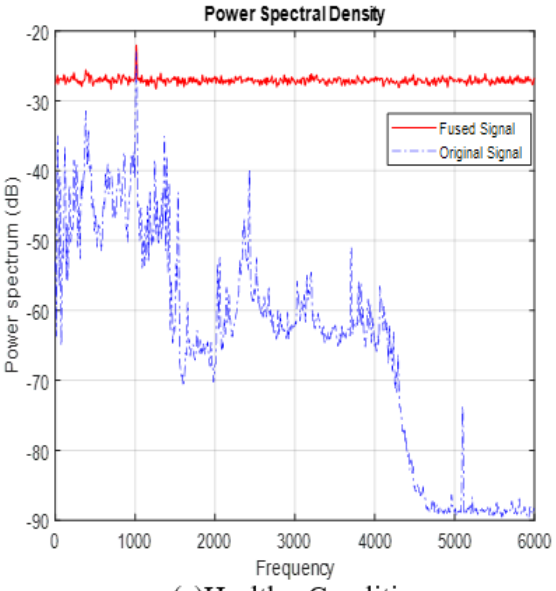

(a)Healthy Condition

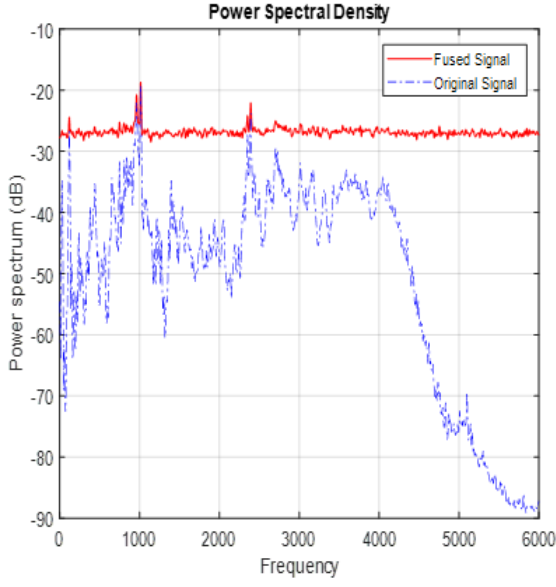

(b) Third Cycle

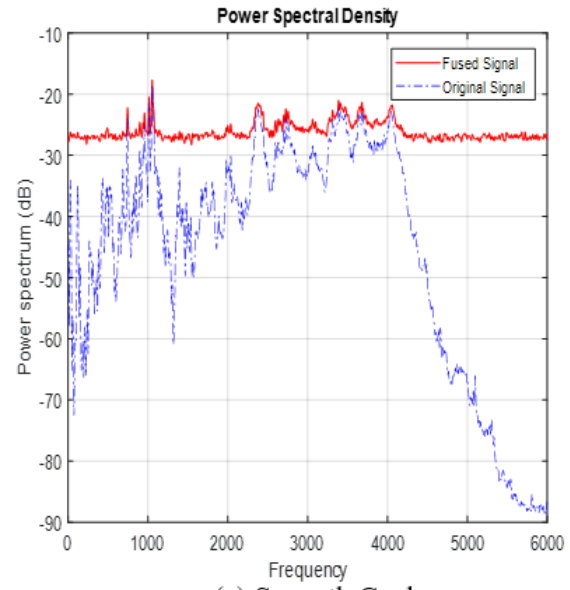

(c) Seventh Cycle

Figure 12. Spectral results under severe process noise (Test \#9) for each aging cycle 


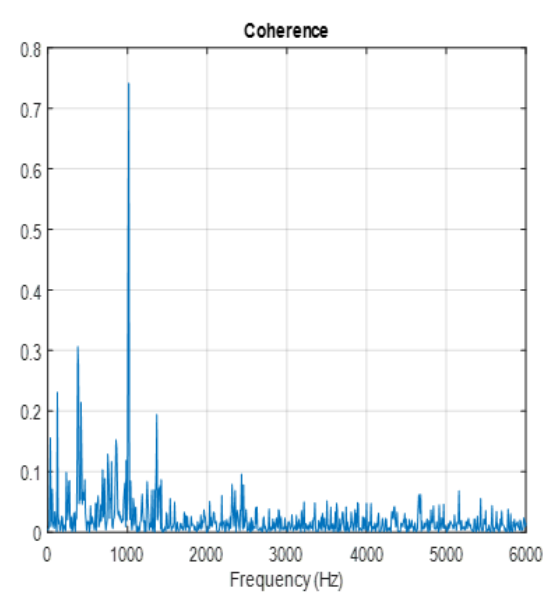

(a)Healthy Condition

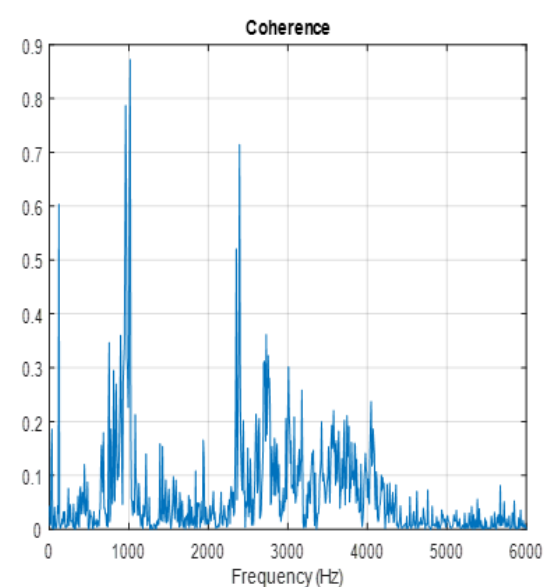

(b) Third Cycle

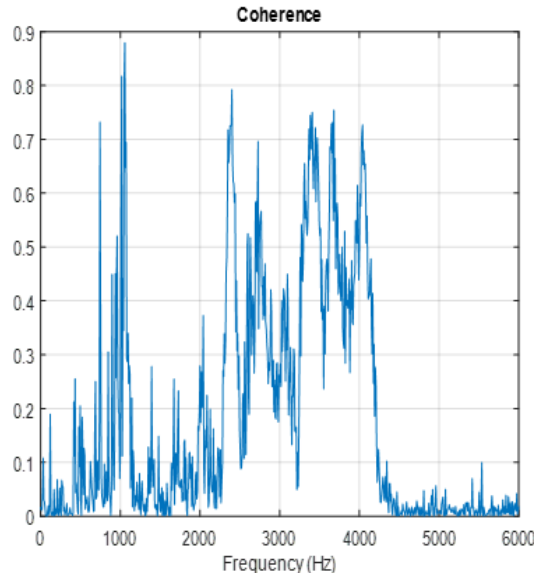

(c) Seventh Cycle

Figure 13. Coherences under severe process noise (Test \#9) for each aging cycle

\section{HEALTH INFORMATION CALCULATION}

The health information (HI) is proposed considering two purposes.

1. To distinguish the process noise from the aging: This topic is totally new for the literature. The problem in the system might be caused by the system itself (as aging) or the sensors (as measurement noises) or the remaining system components (as process noise).

2. To provide an accurate FD under process noise:

As the nature of the algorithm, with the raise of the process noise, a proper and correct FD becomes impossible. Because of that a threshold is presented to specify the possible maximum level of the process noise which allows an accurate FD.

For these aims, two parameters are defined to illustrate the effect of the different process noises on each aging cycle. The calculated parameters $(K$ and $P$ ) are given in Table 9 and Table 10.

$$
\begin{aligned}
& K \triangleq \frac{S N R(\text { Fused signal })}{S N R(\text { Original signal })}=\frac{S N R\left(x_{f}\right)}{S N R(x)} \\
& P \triangleq \frac{P 2 P(\text { Fused signal })}{P 2 P(\text { Original signal })}=\frac{P 2 P\left(x_{f}\right)}{P 2 P(x)}
\end{aligned}
$$

$K$ factor is the signal to noise ratio (SNR) while $P$ factor is the peak to peak $(P 2 P)$ value of the fused signal over the original one. Figures 13-14 are graphical representations of the Tables 9 and 10, respectively. Note that, in these tables $\mathrm{Cyc}_{\mathrm{i}}$ represents $i^{\text {th }}$ Cycle.

According to Figures 14 and $15, K$ factor goes to the saturation while $P$ factor raises with the process noise increment. Furthermore, in each aging cycle, the amplitude of both factors decreases. However, these factors are not practical individually. Hence, the following statement (Eq. (12)) is proposed in this study which is called as health information (HI). Table 11 represents HI values for each aging cycle under various process noise levels.

$$
\text { Health information }=H I \triangleq \log \left(\frac{K}{P}\right)
$$

Figure 16 gives better perspective on $\mathrm{HI}$. The rate of $\mathrm{HI}$ drops down when the process noise grows.

The authors noted that, a threshold is required to discriminate the aged system and a system with process noise. This threshold is needed to comprehend the behavior of the system and distinguish the aging of the IM while the process noise is high. When the spectral interpretation for the fused signals is investigated deeply, some natural thresholds are acquired. It is noted that there are some intervals in which the process noise caches aging. Under low levels of process noise, the aging can be clearly seen on the PSD. However, the higher process noise prevents to detect the aging. Consequently, it is seen that while $\mathrm{HI}$ is lower than -0.3 , process noise becomes dominant over aging. The regions for dominants process noise are shown in Table 11 with grey shaded. The intervals which are identified to interpret $\mathrm{HI}$ are listed below.

- When $H I>0.3$, the system is healthy and the process noise is not dominant.

- When $-0.3<H I<0.3$, although the process noise increases, the aging indications (fault frequencies) can be detected through the fused signal. However, in this region, the PSD and coherence analyses are required for an accurate decision.

- When $H I<-0.3$, the process noise is very dominant, hence, the fused signal is not able to indicate the proper information about system.

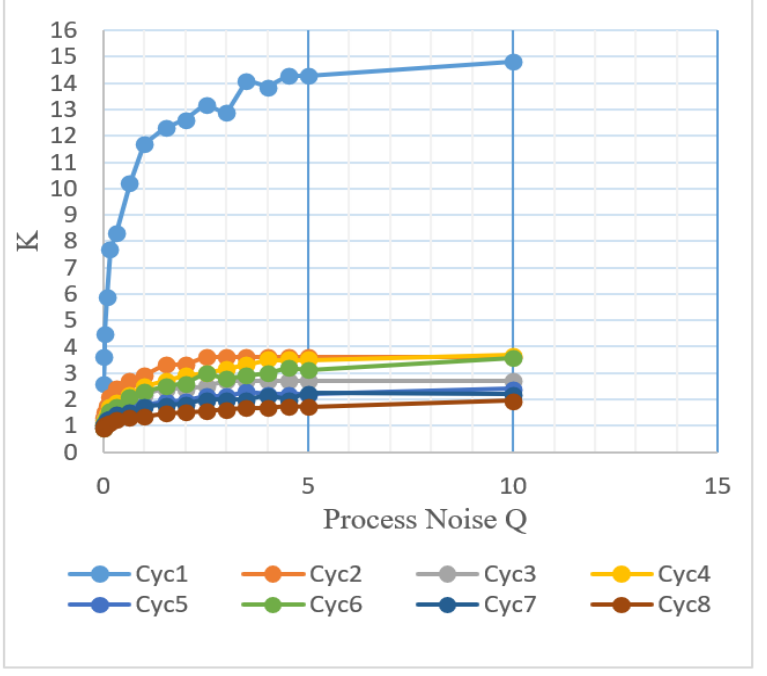

Figure 14. Table 9 graphical representation, $\mathrm{K}$ factor 


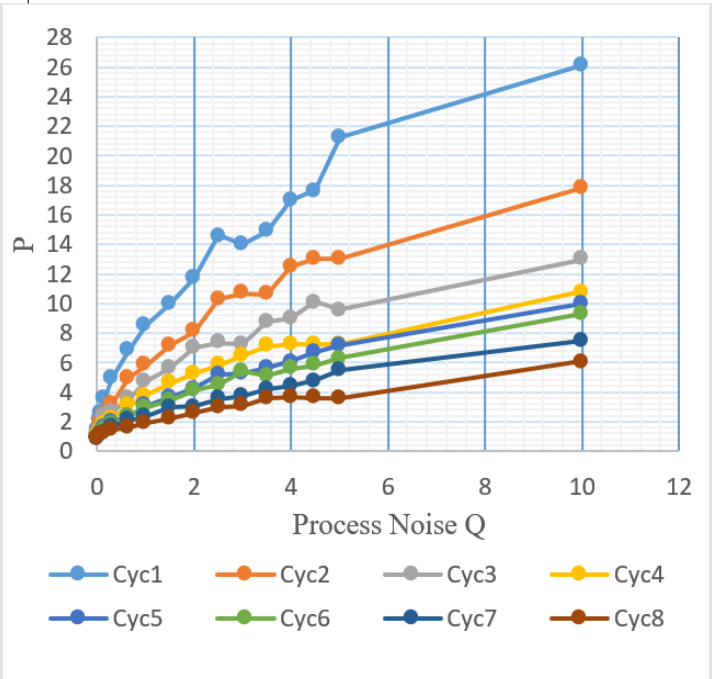

Figure 15. Table 10 graphical representation, $P$ factor

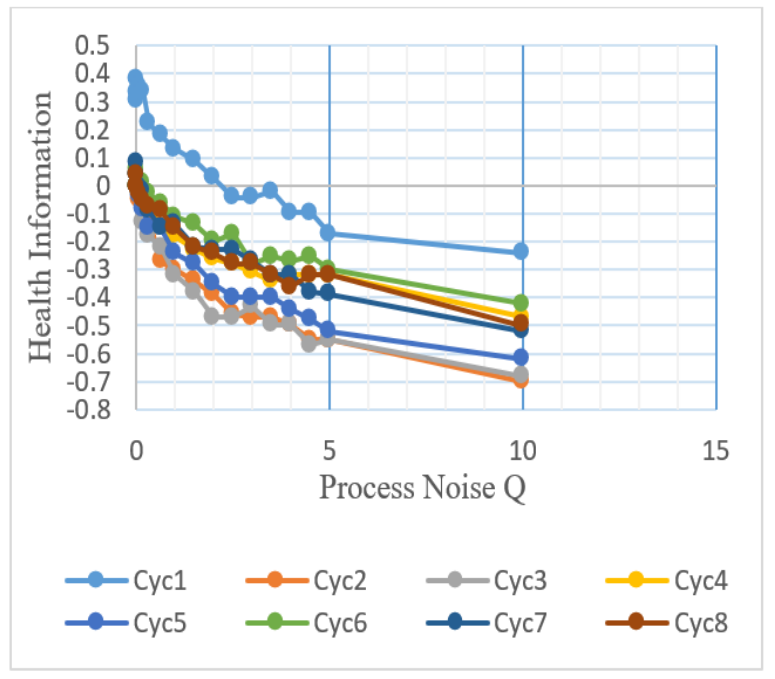

Figure 16. The graphical representation of Health Information

Table 9. $\mathrm{K}$ factor values for the different process noises on each aging cycle

\begin{tabular}{|c|c|c|c|c|c|c|c|c|c|c|c|c|c|c|c|c|c|}
\hline$\frac{Q}{C y c}$ & 0.01 & 0.02 & 0.04 & 0.08 & 0.16 & 0.32 & 0.64 & 1 & 1.5 & 2 & 2.5 & 3 & 3.5 & 4 & 4.5 & 5 & 10 \\
\hline Cyc1 & 2.6 & 3.6 & 4.5 & 5.9 & 7.7 & 8.3 & 10.2 & 11.7 & 12.3 & 12.6 & 13.2 & 12.8 & 14.1 & 13.9 & 14.3 & 14.3 & 14.8 \\
\hline Сус2 & 1.2 & 1.3 & 1.54 & 1.78 & 2.1 & 2.44 & 2.7 & 2.9 & 3.3 & 3.3 & 3.63 & 3.63 & 3.63 & 3.63 & 3.63 & 3.63 & 3.63 \\
\hline Cyc3 & 1.04 & 1.14 & 1.26 & 1.4 & 1.7 & 1.78 & 2.1 & 2.2 & 2.4 & 2.4 & 2.5 & 2.7 & 2.7 & 2.7 & 2.7 & 2.7 & 2.7 \\
\hline Cyc4 & 0.99 & 1.1 & 1.2 & 1.43 & 1.72 & 1.9 & 2.2 & 2.5 & 2.7 & 2.9 & 3 & 3.15 & 3.3 & 3.5 & 3.5 & 3.5 & 3.7 \\
\hline Cyc5 & 0.94 & 1.01 & 1.1 & 1.2 & 1.33 & 1.43 & 1.7 & 1.8 & 1.93 & 1.95 & 2.12 & 2.12 & 2.3 & 2.2 & 2.2 & 2.2 & 2.4 \\
\hline Cyc6 & 0.9 & 1.02 & 1.14 & 1.3 & 1.56 & 1.75 & 2.1 & 2.3 & 2.5 & 2.6 & 3 & 2.8 & 2.9 & 3 & 3.2 & 3.1 & 3.56 \\
\hline Cyc7 & 0.93 & 1.01 & 1.06 & 1.2 & 1.25 & 1.4 & 1.5 & 1.75 & 1.8 & 1.83 & 2 & 2 & 2 & 2.15 & 2 & 2.24 & 2.2 \\
\hline Cyc8 & 0.92 & 0.97 & 1.01 & 1.05 & 1.1 & 1.2 & 1.3 & 1.35 & 1.45 & 1.5 & 1.55 & 1.62 & 1.67 & 1.66 & 1.74 & 1.72 & 1.95 \\
\hline
\end{tabular}

Table 10. $\mathrm{P}$ factor values for the different process noises on each aging cycle

\begin{tabular}{|c|c|c|c|c|c|c|c|c|c|c|c|c|c|c|c|c|c|}
\hline Cyc & 0.01 & 0.02 & 0.04 & 0.08 & 0.16 & 0.32 & 0.64 & 1 & 1.5 & 2 & 2.5 & 3 & 3.5 & 4 & 4.5 & 5 & 10 \\
\hline Cyc1 & 1.3 & 1.5 & 2.1 & 2.6 & 3.5 & 5 & 6.8 & 8.56 & 10 & 11.7 & 14.6 & 14 & 14.8 & 17 & 17.7 & 21.3 & 26.1 \\
\hline Сyc2 & 1.1 & 1.2 & 1.5 & 2 & 2.5 & 3.25 & 5 & 5.8 & 7.2 & 8.1 & 10.3 & 10.7 & 10.6 & 12.5 & 13 & 13 & 17.8 \\
\hline Сус3 & 1.01 & 1.07 & 1.23 & 1.43 & 2.3 & 2.7 & 3.5 & 4.7 & 5.65 & 7 & 7.35 & 7.23 & 8.76 & 9 & 10.1 & 9.6 & 13 \\
\hline Сус4 & 0.96 & 1.02 & 1.2 & 1.4 & 1.8 & 2.2 & 3.1 & 3.8 & 4.6 & 5.3 & 5.8 & 6.45 & 7.1 & 7.25 & 7.25 & 7.25 & 10.8 \\
\hline Cyc5 & 0.86 & 0.96 & 1.08 & 1.3 & 1.6 & 2 & 2.4 & 3.1 & 3.7 & 4.25 & 5.23 & 5.25 & 5.67 & 6.1 & 6.7 & 7.2 & 10 \\
\hline Cyc6 & 0.85 & 0.99 & 1 & 1.27 & 1.5 & 1.86 & 2.4 & 3 & 3.45 & 4.1 & 4.5 & 5.4 & 5.1 & 5.57 & 5.8 & 6.3 & 9.3 \\
\hline Сyc7 & 0.8 & 0.94 & 1 & 1.11 & 1.3 & 1.7 & 2.1 & 2.4 & 3 & 3.06 & 3.5 & 3.75 & 4.2 & 4.45 & 4.8 & 5.5 & 7.46 \\
\hline Cyc8 & 0.85 & 0.93 & 1 & 1.13 & 1.24 & 1.43 & 1.6 & 1.93 & 2.25 & 2.6 & 3 & 3.1 & 3.6 & 3.7 & 3.62 & 3.6 & 6.1 \\
\hline
\end{tabular}

Table 11. HI values for the different process noises on each aging cycle

\begin{tabular}{|c|c|c|c|c|c|c|c|c|c|c|c|c|c|c|}
\hline$\frac{Q}{\text { Cyc }}$ & 0.08 & 0.16 & 0.32 & 0.64 & 1 & 1.5 & 2 & 2.5 & 3 & 3.5 & 4 & 4.5 & 5 & 10 \\
\hline Cyc1 & 0.36 & 0.34 & 0.22 & 0.18 & 0.13 & 0.09 & 0.03 & -0.045 & -0.045 & -0.022 & -0.097 & -0.097 & -0.17 & -0.24 \\
\hline Cyc2 & -0.05 & -0.07 & -0.12 & -0.27 & -0.3 & -0.34 & -0.39 & -0.46 & -0.47 & -0.47 & -0.5 & -0.55 & -0.55 & -0.7 \\
\hline Cyc3 & -0.01 & -0.13 & -0.18 & -0.22 & -0.32 & -0.38 & -0.47 & -0.47 & -0.43 & -0.5 & -0.5 & -0.57 & -0.55 & -0.68 \\
\hline Cyc4 & 0 & -0.022 & -0.065 & -0.15 & -0.18 & -0.23 & -0.26 & -0.28 & -0.31 & -0.34 & -0.32 & -0.32 & -0.32 & -0.47 \\
\hline Cyc5 & -0.036 & -0.081 & -0.15 & -0.15 & -0.24 & -0.28 & -0.35 & -0.4 & -0.4 & -0.4 & -0.44 & -0.48 & -0.52 & -0.62 \\
\hline Сyc6 & 0 & 0.01 & -0.03 & -0.06 & -0.11 & -0.14 & -0.2 & -0.17 & -0.28 & -0.25 & -0.27 & -0.25 & -0.3 & -0.42 \\
\hline Cyc7 & 0 & -0.018 & -0.09 & -0.15 & -0.14 & -0.22 & -0.23 & -0.23 & -0.27 & -0.32 & -0.32 & -0.38 & -0.39 & -0.52 \\
\hline Cyc8 & -0.03 & -0.05 & -0.075 & -0.09 & -0.15 & -0.22 & -0.24 & -0.28 & -0.28 & -0.32 & -0.36 & -0.32 & -0.32 & -0.5 \\
\hline
\end{tabular}

\section{CONCLUSIONS}

In this study, a data fusion application supported by KF for IFE is proposed. It integrates $\mathrm{SV}$ and FD operations in addition to the discrimination of process noise and aging. Vibration signals which are obtained through an accelerated aging process are used in this study. At the first step, the sensors are validated (SV) supported by statistical and spectral analyses. It is demonstrated that FD is also possible through the proposed method regarding the nature of Kalman filter. Then, 
the effect of the process noise on the fused signal is studied while the system is aged. At last, a health rate is proposed to distinguish the aging while process noise exists. According to the results, the following statements are listed as a conclusion:

- An IFE including SV and FD is possible through the proposed technique.

- According to the spectral illustrations, when one sensor is damaged, the proposed method eliminates it. Thus, the fused signal is not affected by the defected sensor.

- When any sensor is damaged, KG drops down significantly.

- When the process is noisy, KG saturates to a constant value.

- In the presence of damaged sensor, the fused signal can detect the frequency components between $2-4 \mathrm{kHz}$ in each aging cycle. Thus, this property renders FD possible.

- Calculating the coherence between the fused and the original signals is the easiest way for FD.

- A health rate can be defined referring the mathematical characteristics of the fused and original signal.

- $\quad$ Some thresholds can be defined for $H I$ indicating if the system and process is healthy or not.

Consequently, the results which are presented in this paper, prove that data fusion through $\mathrm{KF}$ is a powerful and novel technique which is extremely reliable for evaluating the system under various effects such as aging, measurement and process noises.

\section{ACKNOWLEDGMENT}

The authors would like to thank Prof. B. R. Upadhyaya from Nuclear Engineering Department at the University of Tennessee Knoxville, USA, for permission to the use of the experimental data. Also, this study is supported by the Scientific Research Unit of Istanbul Technical University with the project ID: MDK-2018-41044, entitled as "Sensor Validation and Fusion for System Monitoring".

\section{REFERENCES}

[1] Kalman, R.E. (1960). A new approach to linear filtering and prediction problems. Journal of Basic Engineering, 82(1): 35-45. https://doi.org/10.1115/1.3662552

[2] Welch, G., Bishop, G. (1995). An Introduction to the Kalman Filter. University of North Carolina at Chapel Hill.

[3] Daowang, F., Teng, L., Tao, H.Z. (2010). Square-root second-order extended Kalman filter and its application in target motion analysis. IET Radar, Sonar \& Navigation, 4(3): 329-335. https://doi.org/10.1049/iet-rsn.2008.0070

[4] Foulon, E., Forgez, C., Loron, L. (2007). Resistances estimation with an extended Kalman filter in the objective of real-time thermal monitoring of the induction machine. IET Electric Power Applications, 1(4): 549-556. https://doi.org/10.1049/iet-epa:20060356

[5] Xu, J., Song, E.B., Luo, Y.T., Zhu, Y.M. (2012). Optimal distributed Kalman filtering fusion algorithm without invertibility of estimation error and sensor noise covariances. IEEE Signal Processing Letters, 19(1): 5558. https://doi.org/10.1109/LSP.2011.2177495

[6] Assa, A, Janabi-Sharifi, F. (2015). A Kalman filter-based framework for enhanced sensor fusion. IEEE Sensors
Journal, 15(6): $3281-3292$ https://doi.org/10.1109/JSEN.2014.2388153

[7] Kim, S.Y., Kang, C.H., Park, C.G. (2015). A fault detection algorithm using an adaptive fading Kalman filter for various types of GNSS fault. 2015 6th International Conference on Intelligent Systems, Modelling and Simulation, Kuala Lumpur, pp. 113-117. https://doi.org/10.1109/ISMS.2015.18.

[8] TaeDong, P., Kiheon, P. (2008). Kalman filter-based fault detection and isolation of direct current motor: Robustness and applications. 2008 International Conference on Control, Automation and Systems, pp. 933-936. https://doi.org/10.1109/ICCAS.2008.4694628

[9] Wang, J.W., Shen, Y., Zhang, M. (2013). Fault detection for linear switched systems based on multiple Kalman filters method. Proceedings of the 32nd Chinese Control Conference, Xi'an, pp. 6328-6332.

[10] Guo, F.M., Ren, X.M., Li, Z.J., Han, C.W. (2017) Kalman filter based fault detection of dual motor systems. 2017 36th Chinese Control Conference (CCC), Dalian, China, pp. 7133-7137.

[11] Ouhrouche, M., Errouissi, R., Trzynadlowski, A.M., Tehrani, K.A., Benzaioua, A. (2016). A novel predictive direct torque controller for induction motor drives. IEEE Transactions on Industrial Electronics, 63(8): 5221-5230. https://doi.org/10.1109/TIE.2016.2558140

[12] Alonge, F., Cirrincione, M., D'Ippolito, F., Pucci, M., Sferlazza, A., Vitale, G. (2012). Descriptor-type Kalman filter and TLS EXIN speed estimate for sensorless control of a linear induction motor. 3rd IEEE International Symposium on Sensorless Control for Electrical Drives (SLED 2012), Milwaukee, WI, pp. 1-6. https://doi.org/10.1109/SLED.2012.6422806

[13] Boukhnifer, M., Raisemche, A., Diallo, D., Larouci, C. (2013). Fault tolerant control to mechanical sensor failures for induction motor drive: A comparative study of voting algorithms. In IECON 2013 - 39th Annual Conference of the IEEE Industrial Electronics Society, Vienna, pp. 2851-2856. https://doi.org/10.1109/IECON.2013.6699583

[14] Bae, H., Kim, S., Bae, J. (2009). Fault detection and diagnosis of winding short in electric machine based on Park's vector. 2009 7th Asian Control Conference, Hong Kong, pp. 870-874.

[15] Dybkowski, M., Klimkowski, K. (2016). Stator current sensor fault detection and isolation for vector controlled induction motor drive. 2016 IEEE International Power Electronics and Motion Control Conference (PEMC), Varna, pp. 1097-1102. https://doi.org/10.1109/EPEPEMC.2016.7752147

[16] Liu, D.S., Zhao, Y., Yang, B.B., Sun, J.P. (2012). A new motor fault detection method using multiple window $\mathrm{S}$ method time-frequency analysis. International Conference on Systems and Informatics (ICSAI2012), Yantai, pp. 2563-2566. https://doi.org/10.1109/ICSAI.2012.6223577

[17] Xu, B.Q., Zhou, H.H., Sun, L.L., Sun, J.Z. (2007). Weaksignal detection and the application in detection of electric motor faults. 2007 International Conference on Electrical Machines and Systems (ICEMS), Seoul, pp. 1103-1106.

[18] Lee, J., Lee, H., Kim, J., Jeong, J. (2007). Model-based fault detection and isolation for electric power steering system. 2007 International Conference on Control, 
Automation and Systems, Seoul, pp. 2369-2374. https://doi.org/10.1109/ICCAS.2007.4406728

[19] Mohammed, A., Melecio, J.I., Djurović, S. (2019). Stator winding fault thermal signature monitoring and analysis by in situ FBG Sensors. IEEE Transactions on Industrial Electronics, $\quad 66(10)$ : 8082-8092. https://doi.org/10.1109/TIE.2018.2883260

[20] Iorgulescu, M., Alexandru, M., Beloiu, R. (2012). Noise and vibration monitoring for diagnosis of DC motor's faults. 2012 13th International Conference on Optimization of Electrical and Electronic Equipment (OPTIM), Brasov, pp. 724-729. https://doi.org/10.1109/OPTIM.2012.6231919

[21] Jiang, J., Chang, H., Kuo, C. (2016). Operating monitoring and fault types classification for motors through vibration signal. 2016 International Symposium on Computer, Consumer and Control (IS3C), pp. 61-64. https://doi.org/10.1109/IS3C.2016.26

[22] Rahman, M., Azam, T., Saha, S.K. (2010). Motor fault detection using vibration patterns. International Conference on Electrical \& Computer Engineering (ICECE). https://doi.org/10.1109/ICELCE.2010.5700735.

[23] Su, H., Xi, W., Chong, K.T. (2007). Vibration signal analysis for electrical fault detection of induction machine using neural networks. 2007 International Symposium on Information Technology Convergence (ISITC 2007), pp. 188-192. https://doi.org/10.1109/ISITC.2007.54

[24] Bayram, D., Seker, S. (2015). Condition monitoring and fault detection for induction motors by spectral trending and stationary wavelet analysis. Ph. D Thesis of Istanbul Technical https://doi.org/10.1109/COMPEL.2014.6877194

[25] Stack, J.R., Habetler, T.G., Harley, R.G. (2004). Bearing fault detection via autoregressive stator current modeling. IEEE Transactions on Industry Applications, 40(3): 740747. https://doi.org/10.1109/TIA.2004.827797

[26] Trajin, B., Regnier, J., Faucher, J. (2010). Comparison between vibration and stator current analysis for the detection of bearing faults in asynchronous drives. IET Electric Power Applications, 4(2): 90-100. https://doi.org/10.1049/iet-epa.2009.0040

[27] Leite, V.C.M.N., Silva, J.G.B., Veloso, G.F.C., Silva, L.E.B., Lambert-Torres, G., Bonaldi, E.L., Oliveira, L.E.L., (2015). Detection of localized bearing faults in induction machines by spectral kurtosis and envelope analysis of stator current. IEEE Transactions on Industrial Electronics, 62(3): 1855-1865. https://doi.org/10.1109/TIE.2014.2345330

[28] Bianchini, C., Immovilli, F., Cocconcelli, M., Rubini, R., Bellini, A., (2011). Fault detection of linear bearings in brushless AC linear motors by vibration analysis. IEEE Transactions on Industrial Electronics, 58(5): 1684-1694. https://doi.org/10.1109/TIE.2010.2098354

[29] Abdelkrim, C., Meridjet, M.S., Boutasseta, N., Boulanouar, L., (2019). Detection and classification of bearing faults in industrial geared motors using temporal features and adaptive neuro-fuzzy inference system. Heliyon, 5(8): e02046. https://doi.org/10.1016/j.heliyon.2019.e02046

[30] Bo, L., Goddu, G., Mo-Yuen, C. (1998). Detection of common motor bearing faults using frequency-domain vibration signals and a neural network based approach. Proceedings of the 1998 American Control Conference. ACC (IEEE Cat. No.98CH36207), 4: 2032-2036. https://doi.org/10.1109/ACC.1998.702983

[31] Chaudhari, Y.K., Gaikwad, J.A., Kulkarni, J.V. (2014). Vibration analysis for bearing fault detection in electrical motors. 2014 First International Conference on Networks \& Soft Computing (ICNSC2014), pp. 146-150. https://doi.org/10.1109/CNSC.2014.6906681

[32] Ocak, H., Loparo, K.A. (2001). A new bearing fault detection and diagnosis scheme based on hidden Markov modeling of vibration signals. 2001 IEEE International Conference on Acoustics, Speech, and Signal Processing (Cat. No.01CH37221), 5: 3141-3144. https://doi.org/10.1109/ICASSP.2001.940324

[33] Yetis, H., Karakose, M., Aydin, I., Akin, E., (2019). Bearing fault diagnosis in traction motor using the features extracted from filtered signals. 2019 International Artificial Intelligence and Data Processing Symposium (IDAP), $\quad$ pp. 1-4. https://doi.org/10.1109/IDAP.2019.8875901

[34] Seker, S., Kayran, A.H. (2009). Neural network application for fault detection in electric motors. 2009 Australasian Universities Power Engineering Conference, Adelaide, SA, pp. 1-4.

[35] Ojeda, X., Li, G.J., Gabsi, M. (2010). Fault diagnosis using vibration measurements of a Flux-Switching permanent magnet motor. 2010 IEEE International Symposium on Industrial Electronics, pp. 2091-2096. https://doi.org/10.1109/ISIE.2010.5637763

[36] Liu, J., Deng, Z. (2012). Information fusion Kalman filter for two-sensor system with time-delayed measurements. Procedia Engineering, 29: 630-636, https://doi.org/10.1016/j.proeng.2012.01.015

[37] Rhudy, M., Salguero, R., Holappa, K. (2017). A Kalman filtering tutorial for undergraduate students. International Journal of Computer Science \& Engineering Survey, 8: 01-18. https://doi.org/10.5121/ijcses.2017.8101

[38] Wichit, N., Choksuriwong, A. (2015). Multi-sensor data fusion model based Kalman filter using fuzzy logic for human activity detection. International Journal of Information and Electronics Engineering, 5(6). https://doi.org/10.7763/IJIEE.2015.V5.577

[39] Majda, A.J., Tong, X.T. (2018). Performance of ensemble Kalman filters in large dimensions. Communications on Pure and Applied Mathematics, 71(5): 892-937. https://doi.org/10.1002/cpa.21722

[40] Bayram, D., Şeker, S. (2017). Redundancy-based predictive fault detection on electric motors by stationary wavelet transform. IEEE Transactions on Industry Applications, 53(3): 2997-3004. https://doi.org/10.1109/TIA.2016.2622231

[41] Mousavi, S., Bayram, D., Seker, S. (2019). Current data fusion through Kalman filtering for fault detection and sensor validation of an electric motor. 2019 International Aegean Conference on Electrical Machines and Power Electronics (ACEMP) \& 2019 International Conference on Optimization of Electrical and Electronic Equipment (OPTIM), pp.155-160. https://doi.org/10.1109/ACEMPOPTIM44294.2019.9007202 
APPENDIX

Table A.1. The nameplate of the test motor

\begin{tabular}{cc}
\hline Property & Technical Information \\
\hline Motor Type & Premium Efficiency Motor \\
& US Electrical Motors \\
Manufacturer & Division of Emerson Elec. Co. St. \\
& Louis, MO \\
Model Number & $7965 \mathrm{~B}$ \\
Power & $5 \mathrm{HP}$ \\
Phase & 3 \\
Speed & $1,750 \mathrm{rpm}$ \\
Frame Number & $184 \mathrm{~T}$ \\
Frame Type & TCE \\
Voltage & $230 / 460 \mathrm{~V}$ \\
\hline
\end{tabular}

\begin{tabular}{cc}
\hline Current & $13 / 6.5$ \\
Service Factor & 1.15 \\
Frequency & $60 \mathrm{~Hz}$ \\
Power Factor & 0.825 \\
Efficiency & $90.2 \%$ \\
NEMA Design & $\mathrm{B}$ \\
Insulation Class & $\mathrm{F}$ \\
Enclosure & $\mathrm{TE}$ \\
Maximum Ambient & $40^{\circ} \mathrm{C}$ \\
Temperature & $\mathrm{J}$ \\
LR KVA code & Continuous \\
Duty & 1.4 \\
Maximum KVAR & $6206-2 \mathrm{Z}-\mathrm{J} / \mathrm{C} 3$ \\
Shaft End Bearing Type & $6206-2 \mathrm{Z}-\mathrm{J} / \mathrm{C} 3$ \\
Drive End Bearing Type & Z08Z177R190F \\
ID Number &
\end{tabular}

